\title{
Posterior Lingual Gestures and Tongue Shape in Mangetti Dune !Xung Clicks
}

\author{
Amanda L. Miller \\ *Corresponding author: miller.5592@ osu.edu, Tel: +1 614-292-9752, Fax: +1 6142928833 \\ The Ohio State University
}

\begin{abstract}
Clicks differ from pulmonic stops in that, in addition to containing lingual gestures that shape the filtering mechanism of the vocal tract, they also contain lingual "rarefaction gestures" that form the source of the lingual ingressive airstream. The current study uses mid-sagittal lingual ultrasound imaging to investigate 1) overall tongue shape, 2) tongue dorsum and root positions, and 3) dynamic rarefaction gestures involving the tongue dorsum and root, in the four coronal click types recognized by the IPA. The study provides quantitative evidence that the four click types differ in overall tongue shape. Additionally, results show that the palatal click has a farther back dorsal constriction than the three pre-palatal clicks, and the tongue root is raised and bunched in the upper pharynx in one variant of the palatal click, but involves retraction of the tongue root proper in the lower pharynx in the alveolar click. A second variant of the palatal click involves posterior gestures more similar to those found in the alveolar click. Results provide evidence that the kinematics of the posterior part of the tongue are important in describing click production, and shed light on synchronic and diachronic sound patterns involving the palatal click in Kx'a languages.
\end{abstract}

\section{Keywords}

Click consonants, ultrasound imaging, tongue shape, tongue dorsum, tongue root, rarefaction gestures

\subsection{Introduction}

There are Consonant-Vowel co-occurrence restrictions found between clicks and front vowels in most southern African non-Bantu click languages. Traill (1985) called this constraint The Back Vowel Constraint. Miller-Ockhuizen (2003) and Miller (2010) have suggested that differences in the posterior constrictions of clicks are the phonetic bases of these restrictions, but articulatory differences among the posterior gestures in the four click types have not previously been investigated quantitatively. This study intends to fill this gap by providing a description of overall tongue shape, tongue dorsum and root positions just prior to the anterior release, and posterior gestures during the closure (rarefaction) phase of clicks.

The IPA (2006) recognizes four coronal click types: dental [l], alveolar [!], lateral [\|], and palatal [ł], which all contrast in Mangetti Dune !Xung. These four click types are known to differ in the location and shape of the anterior constrictions. While clicks are produced similarly to pulmonic stops in that they have a shutting phase, a closure phase, and a release phase (Abercrombie 1967); their production is unique in that it also involves "rarefaction gestures" occurring during the closure phase, which decrease the pressure in the lingual cavity formed between the two constrictions (Thomas-Vilakati 2010). These gestures occur prior to the release of the anterior constriction of the click, which allows air to rush into the lingual cavity. The rarefaction gestures are responsible for the decrease in pressure that results in the loud acoustic noise-bursts that are characteristic of clicks. In the current study, ultrasound imaging is used to investigate posterior lingual kinematics that contribute to rarefaction in clicks. 


\subsection{Previous Studies of Click Production}

Previous articulatory descriptions of clicks have mainly been undertaken outside of the laboratory in remote areas of southern and East Africa. These studies have relied on static palatography and linguography. Such techniques, which utilize photographing tongue-palate contact using a dental mirror, are superior to ultrasound for studying anterior constrictions in consonants, given the difficulty of imaging the tongue tip with ultrasound (Stone 2005). However, static palatography provides incomplete data on posterior constrictions of clicks given the difficulty of covering the soft palate with a charcoal mixture.

Preliminary descriptions of tongue shapes in the four coronal click types in Mangetti Dune !Xung are provided in Miller, Scott et al. (2009) and Miller (2013).

\subsubsection{Posterior Constriction Locations}

Posterior constriction locations of clicks have long been described as velar, where velar refers to the contact point being at the velum (Doke 1923; Beach 1938; Traill 1985; Ladefoged and Traill 1994; Ladefoged and Maddieson 1996). The use of the term velar has been carried into phonological representations, where clicks have been described using the feature [+back], grouping together clicks and [k] into a single natural class. Miller, Namaseb and Iskarous (2007) and Miller, Brugman et al. (2009) have provided lingual ultrasound studies of the posterior constriction locations of clicks in Khoekhoe and $\mathrm{N} \mid$ uu. Due to the $30 \mathrm{fps}$ frame rate that was used in these earlier studies, there was a great degree of variability in the constriction location results. Miller, Namaseb and Iskarous (2007) provide quantitative measurements of the tongue root positions of the alveolar and palatal click types in Khoekhoe, and the data show that the posterior constriction of the palatal click type is behind that of the alveolar click type, and that the different click types involve different overall tongue shapes, including differences in tongue front, body, dorsum, and root postures. They have shown that the posterior constriction location of the alveolar click type is uvular, and the posterior constriction location of the palatal click type is uvulopharyngeal. Miller, Brugman et al. (2009) have provided qualitative evidence that a similar difference exists among these two click types in $\mathrm{N} / \mathrm{uu}$. They note that there are two distinct posterior constrictions produced by the tongue dorsum and the tongue root in the alveolar click type in N|uu. Investigation of posterior lingual kinematics was not possible in these earlier $30 \mathrm{fps}$ ultrasound studies.

Thomas-Vilakati (2010) provides a quantitative study of the production of the three contrastive click types (Dental, Palato-alveolar and Lateral) in the Bantu language Zulu using static palatography, linguography, electropalatography and airflow. Due to the difficulty of covering the soft palate with a pseudo-palate, electropalatographic data of the palato-alveolar click type in Zulu shows little to no contact between the tongue dorsum and the front edge of the pseudo-palate. Thus, the results provide evidence that the posterior constriction involved in the palato-alveolar click type is farther back than that found in the dental and lateral click types, where the contact of the posterior constrictions are clearly seen on the pseudo-palate. The airflow data also provides indirect evidence of a post-velar constriction in the palatalalveolar click type.

\subsubsection{Tongue Movement during Click Closures}

Movement of the tongue tip and tongue dorsum have been shown to occur during click closures. Ladefoged and Traill (1994) have shown that the palatal click type in !Xóõ involves retraction of the 
tongue tip. Thomas-Vilakati's Zulu study shows that the dental click type involves no tongue dorsum retraction, while the palato-alveolar click type involves some degree of tongue dorsum retraction during rarefaction. Her study also surmises movements of the tongue root from airflow data.

The current study differs from earlier studies in that it provides novel data on the dynamics of posterior lingual movements in clicks using high frame rate ultrasound data obtained using the CHAUSA method (Miller and Finch 2011). Ultrasound allows us to directly view the rear part of the tongue dorsum and the tongue root, which cannot be viewed with electropalatography. The current study includes all four contrastive coronal click types and the retracted velar pulmonic stop [k] that occurs in the [a] context. High frame rate ultrasound makes it possible to view lingual dynamics that occur over short temporal intervals, by providing images of the majority of the tongue every $8.77 \mathrm{~ms}$ with good spatial clarity.

\subsection{Qualitative Description of Tongue Shape and Rarefaction Gestures in Mangetti Dune!Xung clicks}

Figure 1 provides two frames taken from lingual ultrasound videos of the production of a single token of three of the four contrastive coronal click types that occur in Mangetti Dune !Xung. These productions are from a male speaker (JF). The first image of the tongue (labeled Frame 1) is the first identifiable frame in the closure phase (the first frame where both constrictions are in place). The second image (labeled Frame 2) is the last frame prior to the anterior release - that is, the last frame in the closure phase. Figure 1 provides an illustration of the phenomena under investigation. Overall tongue shapes and indirect evidence of differences in lingual kinematics among the four click types are visible. A video in the supplemental material provides the raw ultrasound videos of all four click types produced by the same speaker $(\mathrm{JF})$ to allow direct viewing of the kinematics.

I will focus first on tongue shape differences found in the back part of the tongue in the frames labeled Frame 2 on the right side of Figure 1, and then turn to describing the rarefaction gestures, which are visible through comparing differences in the tongue shapes in Frames 1 and 2. Tongue Dorsum Constriction Locations (TDCL) and Tongue Root Constriction Locations (TRCL) are labeled in the images. Lingual cavities are also labeled in the ultrasound images of the second frame, to help the reader interpret the figures, though tongue body lowering involved in rarefaction is not investigated in the current study.

The three click types differ in their overall tongue shapes, and in the angle of the overall tongue from front to back. The height of the coronal and dorsal constrictions is relatively even in the dental and alveolar click types, leading to the visual impression that the tongue slope is relatively flat from front to back in these two clicks. A similar flat tongue shape is seen in the supplemental video of these click types. In the palatal click type, the tongue dorsum constriction is much lower in height than the coronal constriction, which suggests that the dorsal constriction is in the uvulo-pharyngeal region, not in the back dorsal region, in the dental and alveolar click types.

Differences in the Tongue Dorsum constriction locations (TDCL) just prior to the anterior release of the clicks are visible among the three click types. Namely, the palatal click type has a farther back posterior constriction than the dental and alveolar click types. This observation is in keeping with the description of differences in the back constrictions of the alveolar and palatal click types in Khoekhoe (Miller, Namaseb and Iskarous 2007) and N|uu (Miller, Brugman et al 2009). The dental click type was not described in these earlier studies. 
The tongue root positions are at similar locations on the horizontal dimension among the three click types, although the height of the tongue root constrictions differs among the click types. The tongue root constriction in the palatal click types is lower than that seen in the dental and alveolar click types, which suggests that either a different part of the tongue root is involved, or that the tongue root is raised and bunched. In the dental and alveolar click types, the tongue root constriction involves the tongue root proper, while in the palatal click type, the farthest back part of the tongue in the pharynx is actually the back part of the dorsal constriction in the upper pharyngeal region. Therefore, it is possible to interpret the part of the tongue seen in the upper pharyngeal region as part of the dorsal constriction, rather than as a separate constriction of the tongue root. 


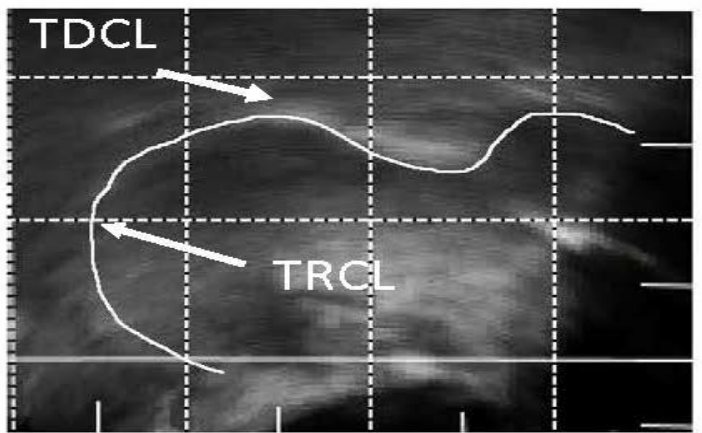

Frame 1, Alveolar click

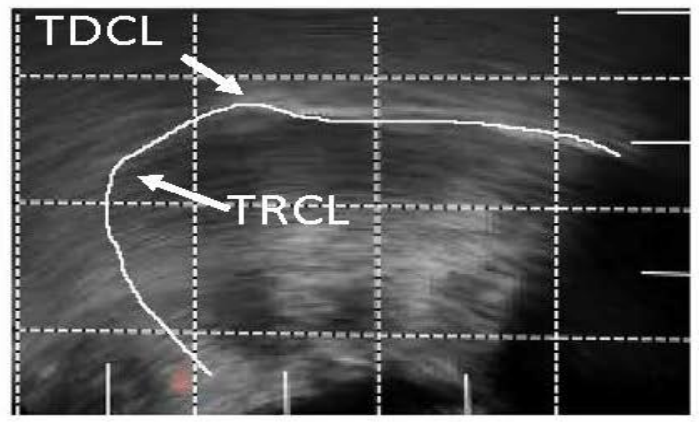

Frame 1, Dental click

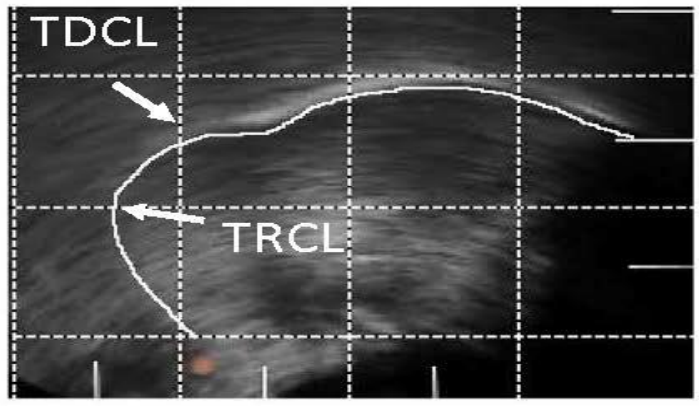

Frame 1, Palatal click

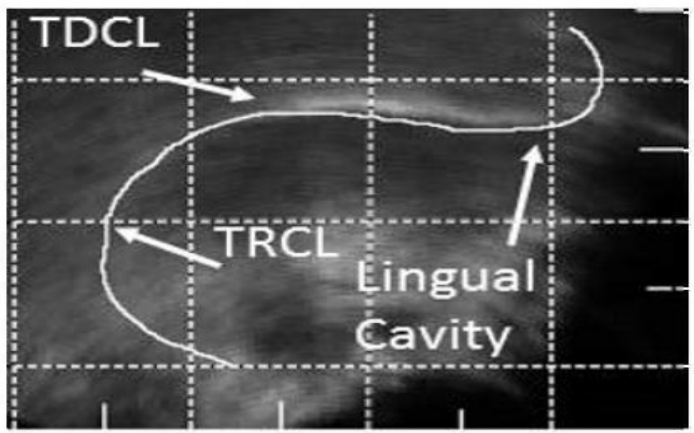

Frame 2, Alveolar click

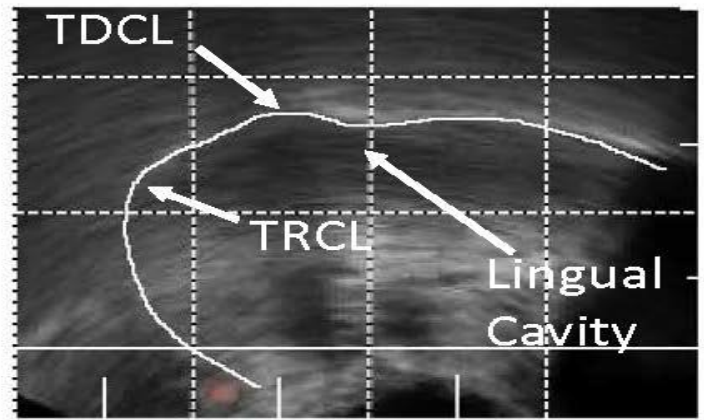

Frame 2, Dental click

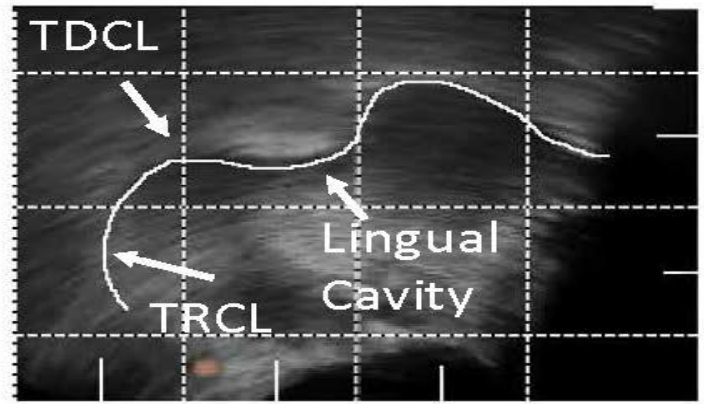

Frame 2, Palatal click

Figure 1. Raw ultrasound images of two frames of the Dental, Alveolar and Palatal click types produced by male speaker JF, illustrating the articulatory landmarks that are analyzed in the current study (Frame 1 is the first frame in the closure phase where both the coronal and dorsal constrictions are in place, and Frame 2 is the last frame in the closure phase, which is within $8.77 \mathrm{~ms},+/-4.39 \mathrm{~ms}$ of the coronal release.) Note that these are raw images that have not been head corrected, but they are expected to be fully internally consistent, since these tokens were all recorded in the same headset seating with the same probe placement. Tongue Dorsum Constriction Locations (TDCL) and Tongue Root Constriction Locations (TRCL) have been labeled, as has the Lingual Cavity in Frame 2 where it is present in all of the clicks. ${ }^{1}$ The dotted grid lines mark $2 \mathrm{~cm}$ intervals both horizontally and vertically. The solid tick marks that occur between the dotted grid lines on both dimensions mark intervening $1 \mathrm{~cm}$ intervals.

\footnotetext{
1 The Lateral click images are not included here, because the individual ultrasound frames by themselves are quite difficult to interpret, without visualizing tongue movement. For all of the click types, the reader is advised to view the supplemental video that provides high frame rate videos of each click type, and single step through the video using software that allows this control
} 
Differences in rarefaction gestures can be surmised when comparing Frame 1 tongue positions to Frame 2 tongue positions. In the palatal click type, the highest part of the tongue dorsum, which is assumed to be the part that touches the soft palate, is more forward and higher in Frame 1 than in Frame 2. Similarly, the tongue root constriction (or the back of the dorsal constriction as we might call it) is higher in Frame 1 than in Frame 2. These two differences surely go hand in hand, since the posterior part of the tongue (dorsum and root) seem to be moving together, not independently, in this click type. In the dental click type, the tongue dorsum and tongue root positions both are more forward in Frame 2 than in Frame 1, signaling advancement of the tongue dorsum and root during rarefaction, not retraction. In this token of the alveolar click type, the Tongue Dorsum and Tongue Root positions are fairly stable between Frames 1 and 2, displaying neither advancement nor retraction. However, other tokens display tongue root retraction.

\subsection{Goals of the Current Study}

The current study has three goals. The first goal is to quantitatively describe and compare / contrast the overall tongue shapes of the four contrastive coronal click types. The second goal is to provide quantitative measures of the posterior static constriction locations (tongue dorsum and root positions) at the time that is most relevant to the acoustic properties of the click bursts - the frame just prior to the anterior release (Frame 2 in Figure 1). The third goal is to quantitatively investigate the posterior rarefaction gestures involving the tongue dorsum and root in the production of the four click types. The research questions, and hypotheses are provided, along with mnemonic names for the hypotheses to help the reader remember them.

Research Question 1 (Q1) addresses the first goal of the paper - overall tongue shape differences among clicks.

Q1. How do the overall tongue shapes of the four contrastive coronal click types compare to each other?

H1. The dental and palatal click types have a relatively flat tongue shape with broad anterior and posterior constrictions and relatively shallow tongue body wells. The alveolar and lateral click types have more concave tongue shapes with narrow anterior constrictions and deep tongue body wells.

H1 will be referred to throughout the paper as the "flat vs. concave tongue shape" hypothesis.

Research Question 2 (Q2) addresses goal 2, by investigating differences in the constriction locations of the tongue dorsum and tongue root just before the anterior release.

Q2. Do the farthest back posterior lingual tongue dorsum and root positions in the consonants that cooccur with [i] $\{[\mid],[\neq])$ differ from those found in the consonants that co-occur with [əi] $\{[!]$, [\|]\}, and those that co-occur with $[\mathrm{a}]\{[\underline{\mathrm{k}}]\}$ ?

H2a. The tongue dorsum and root constriction locations are farthest back in the consonants that co-occur with [a], followed by the clicks that co-occur with [əi], and the clicks that co-occur with [i].

H2b. The palatal click has farther back tongue dorsum and root constrictions then the pre-palatal clicks.

(they are too fast to view at full speed, and get anything out of them). Quick Time Video is one such freely available software that allows viewing videos frame by frame across operating systems. 
$\mathrm{H} 2 \mathrm{a}$ will be referred to as the "Vowel Context Hypothesis", and H2b will be referred to as the "Front Constriction Location Predicts Back Constriction Location” Hypothesis.

The third goal of the paper is addressed in Research Question 3 (Q3).

Q3. Do the alveolar and lateral click types involve posterior rarefaction gestures (Tongue Dorsum and /or Tongue Root retraction) during the closure phase that are not exhibited in the dental and palatal click types?

H3a. The alveolar and lateral click types involve retraction of the tongue root into the mid oro-pharynx, while the dental and palatal click types involve bunching of the tongue root into the upper pharynx.

H3b. The palatal click type displays Tongue Dorsum/Root retraction, in response to tongue tip retraction.

$\mathrm{H} 3 \mathrm{a}$ will be referred to as the "Tongue Root Retraction vs. Tongue Bunching hypothesis," and H3b will be referred to as the "Tongue Tip Retraction Conditions Tongue Dorsum / Root Retraction" hypothesis.

The current study presents five analyses. The first analysis provides a quantitative description of overall tongue shape of the four click types to address Q1. The second and third analyses provide tongue dorsum and tongue root constriction locations just prior to the release of the anterior constriction of the four clicks to address Q2. The fourth and fifth analyses investigate the dynamics of the tongue dorsum and root that contribute to rarefaction gestures to address Q3. The five distinct analyses provide a comprehensive picture of the posterior lingual gestures involved in the production of the four coronal click types and [k].

\subsection{The Language and Speakers}

\subsection{Language Background and Speakers}

Mangetti Dune !Xung is spoken in the Tsumkwe west area of the eastern Otjizondjupa region of Namibia in the towns of Mangetti Dune and Omataku, as well as in the town of Omega, near Baghani on the Caprivi strip. There are approximately 500 speakers of the language in the Tsumkwe west area, and even fewer speakers in Omega. The language is endangered. The language was originally spoken in northern Namibia and southern Angola, and some of the elder speakers currently residing in Namibia fled Angola during the civil war - though most of their children and grandchildren have been born in Namibia. In 1990, with the advent of Namibian Independence from South Africa, some of the !Xung speakers residing in Namibia relocated to South Africa, so there are also speakers of the language residing on the farm Platfontein near Kimberly, South Africa. The language is a member of the Juu subgroup of the Kx'a language family (Heine and Honken 2010). According to Sands' (2010) classification, the language is a member of the Northern branch of the subgroup. According to Heine and König's (2012) classification, Mangetti Dune !Xung is a member of the Northwestern branch of the subgroup.

Four speakers who were born and raised in Mangetti Dune participated in the current study: Rooi Jenggu Fransisko (JF, Male), Martin \|Oce Aromo (MA, Male), Sabine Towe Riem (SR, Female), and Caroline Thumbo Kaleyi (TK, Female). All four speakers were in their early twenties when recording took place in 2008. Speaker SR's data is not presented here, due to the small number of usable tokens. 


\subsection{Sound Inventory}

The sound inventory of Mangetti Dune !Xung was arrived at through the course of several prolonged field trips to Mangetti Dune, Namibia between 2007 and 2013 by Amanda Miller and Bonny Sands. A lexicon is in progress in collaboration with several of our language consultants (Aromo et al 2008). The consonant inventory of Mangetti Dune !Xung is provided in Tables 1 and 2. Following the IPA (2006) consonant chart organization, and the consonant inventory of $\mathrm{N} \mid \mathrm{uu}$ provided in Miller, Brugman et al. (2009), the consonant chart is broken up into two separate tables that contain consonants with different airstream mechanisms. Table 1 provides the pulmonic and glottalic airstream consonants, while Table 2 provides the lingual (a.k.a. velaric) airstream consonants, as well as the contour segments in airstream (linguo-pulmonic and linguo-glottalic consonants). The contour segments in airstream are structurally similar to affricates. There are a total of 88 contrastive consonants in the language.

Table 3 contains the inventory of modal vowels. There is a simple five-vowel inventory. However, there are a total of 55 phonemic vowels once the contrasts in phonation type, oral vs. nasal vowel contrasts, and diphthongs are included. The nasalized modal vowel inventory contains the back vowels, $\left[i^{\mathrm{n}}, \mathrm{u}^{\mathrm{n}}, \mathrm{a}^{\mathrm{n}}\right]$. There are 5 breathy monophthongs, [ị, ụ, ẹ, ọ, a, ], as well as two breathy nasal monophthongs, [ụn ${ }^{\mathrm{n}}, \mathrm{a}^{\mathrm{n}}$ ], that occur in the language. The glottalized vowels, [u'u, e'e, o'o, a'a] also occur, as well as the nasalized glottalized vowel $\left[\mathrm{u}^{\prime} \mathrm{u}^{\mathrm{n}}\right]$, the back epiglottalized vowels $\left[\mathrm{o}^{z}, \mathrm{a}^{z}\right]$, and their nasalized epiglottalized counterparts $\left[\mathrm{o}^{2 \mathrm{n}}, \mathrm{a}^{2 \mathrm{n}}\right]$.

Modal diphthongs that occur are [əi], [əu], [əо], [əе], [ui] and [oe]. There are also the nasalized diphthongs $\left[\partial^{n} i^{n}\right],\left[\partial^{n} u^{n}\right],\left[u^{n} i^{n}\right],\left[o^{n} a^{n}\right]$, and $\left[a^{n} o^{n}\right]$. The superscripted ' $n$ ' notes nasalization of the preceding vowel. The breathy diphthongs, [ọa], [ọ ${ }^{\mathrm{n}}$ ], [ọe], [ạo] and [ụi], the glottalized diphthongs

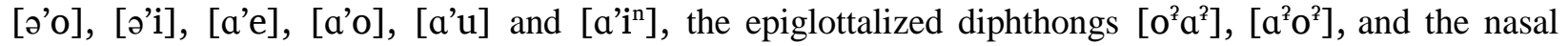
epiglottalized diphthongs $\left[\mathrm{o}^{2 \mathrm{n}}, \mathrm{a}^{\mathrm{2n}}\right]$ also occur.

Schwa is an allophone of / $\mathrm{a} /$ that occurs before a high vowel, [i] or [u], in the same or following syllable, or before a nasal coda, [m] or [y]. Similarly, [ə’ə] is an allophone of /a'a/, and [ə]] is an allophone of /ạ/, that occur preceding [i] or $[\mathrm{u}]$ in a following syllable. The lax vowels $[\mathrm{I}],[\varepsilon],[\mathrm{v}]$ and $[0]$ are limited to the first vocalic position of a bisyllabic word. They never occur in either vowel slot of CVV words, or in the second syllable of bisyllabic words, which suggests that they may be allophones of the tense counterparts.

The phonemic nature of the four click types in the language is justified with the near-minimal sets provided in (1) from Aromo et al.'s (2008) lexicon. This language has an extremely large number of contrastive sounds -88 consonant phonemes, 55 vowel phonemes when vowels that have contrastive phonation types and contrastive nasality, which signal contrasts, are included, as well as 4 tone levels that combine to make up 7 possible word tone patterns. Given this large number of contrastive properties, the probability of two words being a true minimal pair is extremely low, and the probability of there being a minimal quadruplet is even lower.

(1) Near minimal sets illustrating the contrastive nature of the four voiceless and voiced click types

\begin{tabular}{|c|c|c|c|c|c|c|}
\hline 'mortar' & |àò & 'buffalo' & g|áá & 'spouse' & g|ưưú & 'night' \\
\hline 'mortar' & \|àò & 'to die (pl.)' & g\|àà & 'year, rain' & g!ưưu & 'belly' \\
\hline 'death' & & & głàà & 'to put down' & g\|ưứ & 'water' \\
\hline
\end{tabular}


As in Ju|'hoansi (Miller-Ockhuizen 2003), click consonants only occur root-initially. This is a property of all non-Bantu southern African click languages (see Traill 1985), but not East African click languages.

Table 1 Pulmonic consonant inventory

\begin{tabular}{|c|c|c|c|c|c|c|c|c|c|c|c|c|c|}
\hline \multicolumn{14}{|c|}{ PULMONIC AIRSTREAM } \\
\hline \multirow[b]{2}{*}{ Stop } & \multicolumn{2}{|l|}{ Bilabial } & \multicolumn{2}{|c|}{ Alveolar } & \multicolumn{2}{|c|}{ Palatal } & \multicolumn{4}{|c|}{ Velar } & \multicolumn{2}{|l|}{ Uvular } & \multirow{2}{*}{$\begin{array}{l}\text { Glottal } \\
?\end{array}$} \\
\hline & $\mathrm{p} \mathrm{p}^{\mathrm{h}} \mathrm{b} \mathrm{b}^{\mathrm{f}}$ & $\mathrm{t} \quad \mathrm{t}^{\mathrm{h}}$ & $\mathrm{d} \mathrm{d}^{\mathrm{f}}$ & -- & ---- & - & $\mathrm{k}$ & $\mathrm{k}^{\mathrm{h}}$ & g & $g^{\mathrm{fi}}--$ & $-\quad--$ & -2 & \\
\hline Affricate & & $\begin{array}{cc}\text { ts } & \text { ts }^{\mathrm{h}} \\
& \text { ts } \chi \\
& \text { t } \chi\end{array}$ & $\mathrm{ds} d \mathrm{z}^{\mathrm{f}}$ & & $\begin{array}{cc}t \int^{\mathrm{h}} & \mathrm{f}^{\mathrm{s}} \\
\mathrm{t} \chi & \text { ts } \chi\end{array}$ & & & & & & & & \\
\hline Nasal & $\mathrm{m} \mathrm{m}^{\mathrm{f}}$ & & $\mathrm{n} \quad \mathrm{n}^{\mathrm{f}}$ & & & & & & g & & & & \\
\hline Prenasalized & & & ${ }^{\mathrm{n}} \mathrm{d}$ & & & & & & & & & & \\
\hline Fricative & & & & & & 3 & & & & $\chi$ & & & fi \\
\hline Approximant & & & & 1 & $\mathrm{j}$ & & & & & & -- & & -- \\
\hline GLOTTALIC AI & STREAM & & & & & & & & & & & & \\
\hline Stop & & $\mathrm{t}^{\prime}$ & & & & & & & & & & & \\
\hline Affricate & & $\begin{array}{l}\text { ts' } \\
\text { tx }\end{array}$ & $\begin{array}{l}\mathrm{ds}, \\
\mathrm{d} s \chi^{\prime}\end{array}$ & & t $\int^{\prime} d \int^{\prime}$ & & $\mathrm{k} \chi^{\prime}$ & & & & & & \\
\hline
\end{tabular}

Table 2 Lingual consonant inventory LINGUAL AIRSTREAM

\begin{tabular}{|c|c|c|c|c|c|c|c|}
\hline & Dental & & & veolar & & Pals & \\
\hline & & & Central & & Lateral & & \\
\hline Stop & $\left.\right|^{\mathrm{h}}$ & $\mathrm{g}|\mathrm{g}|^{\mathrm{f}}$ & $!^{\mathrm{h}}$ & g! g! & $\|^{\mathrm{h}}$ & ${ }^{\mathrm{g}}\left\|{ }^{\mathrm{g}}\right\|^{\mathrm{f}}$ & $g_{\neq} g^{g} f^{f i}$ \\
\hline Nasal & $\mathrm{y}^{\circ}\left|\quad \mathrm{\eta}^{\circ}\right|^{\mathrm{h}}$ & 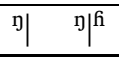 & ग̊! & ग! & 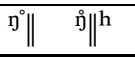 & $\mathrm{g} \| \mathrm{y}^{\mathrm{j}}$ & $\mathrm{p}_{\neq} \mathrm{y}^{\mathrm{f}}$ \\
\hline LINGUO-P & LMONIC & IIRSTRE & & & & & \\
\hline Affricate & $\left.\begin{array}{ll}x & g\end{array}\right|^{x}$ & & $9 ! x$ & & $\left\|^{\chi} \quad 9\right\|^{x}$ & 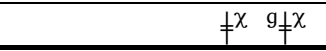 & \\
\hline LINGUO-C & OTTALIC & AIRSTRI & AM & & & & \\
\hline Affricate & $\left|\begin{array}{ll}x^{\prime} & g\end{array}\right|^{\prime}$ & & $!^{\prime} \quad g !^{\prime}$ & & $\begin{array}{ll}\|^{\prime} & 9\end{array} \chi^{\chi^{\prime}}$ & $\neq x^{\prime} q_{\neq} x^{\prime}$ & \\
\hline
\end{tabular}

Table 3 Modal vowel inventory

\begin{tabular}{ll}
\hline $\mathrm{i}$ & $\mathrm{u}$ \\
$\mathrm{e}$ & $\mathrm{o}$ \\
\hline
\end{tabular}

\subsection{Method and Materials}

\subsection{Ultrasound Data Collection}

\subsubsection{Wordlist and Recording}

Lingual ultrasound (US) and acoustic data were simultaneously collected in Mangetti Dune, Namibia using the Corrected High Frame Rate Anchored Ultrasound with Software Alignment (CHAUSA) method at $114 \mathrm{fps}$, which yields an image of the tongue every $8.77 \mathrm{~ms}(+/-4.4 \mathrm{~ms})$, and is accurate spatially to within $1 \mathrm{~mm}$. The CHAUSA method is described in detail in Miller and Finch (2011). Words containing all four initial click types in the /i/ context were collected. The wordlist is provided in Table 4, which contains the orthographic form, phonetic transcription, and English gloss for each word, along with the number of analyzable mid-sagittal lingual ultrasound videos of each word. 
Twelve repetitions ( 4 takes, with 3 repetitions in each take) of each word in Table 4 were initially collected, but some of the ultrasound tokens were unusable, due to either poor image quality, or to accidental recording of the videos at a different frame rate than intended. There were also issues with data transfer in the field, which required the collection of additional data. Some of the transfer issues were resolved back in the lab, resulting in additional tokens of the alveolar click type for one speaker. These problems resulted in an unbalanced data set. The words were recorded in the frame sentence in (2). The initial sound of each of the target words was analyzed. The ' $\mathrm{k}$ ' in the word $k a$ 'it' in the frame sentence is used as a reference consonant.

(2) Ma oo kx’ui [má ù k' $\mathrm{k}^{\chi}$ í $1^{\text {st }}$ sg. said 'I said ka djala. kà dzàlà] it well. well'.

Three repetitions of each phrase were recorded together in each type of file (US, audio, and head video). One repetition of the entire word-list is referred to here as a take. The number of takes recorded in a single headset seating ranged from one to three, depending on the comfort level of the speaker with a particular headset seating, and the amount of time it took to record the takes. Headset wear was limited to $1 / 2$ - 1 hour at a time, which is even more restrictive than the 1 to $11 / 2$ hours recommended by Articulate Instruments (2008). It typically took an hour to record two takes of the wordlist. ${ }^{2}$

A swallow was recorded at the beginning of each headset seating, which was later used for palate tracing (see Section 3.2.2.). The swallow was recorded in the following frame sentence to allow a consonant on each side of the swallow for data alignment purposes.

(3) g!úm _(swallow)_ gùm

Speech rate was relatively controlled, as speakers needed to produce three repetitions of the phrase within the 8-second ultrasound recording window, which is the maximum achievable window when recording at the $114 \mathrm{fps}$ frame rate. The experimenters corrected speakers if they spoke too slowly or too fast, and /or left large or inconsistent length pauses in between words within a phrase, or between the three repetitions of the phrase. Such recordings were thrown out. The resulting video and audio recordings (takes) contained three evenly timed and evenly spaced repetitions of each of the words in the frame sentence.

The different vowel allophones found following the different click types seen in Table 4 are due to the Back Vowel Constraint, which results in the [i] allophone of /i/ following the dental and palatal click types and the [əi] allophone of /i/ following the alveolar and lateral click types. This co-occurrence pattern has been described in !Xóõ (Traill 1985), Ju|'hoansi (Miller-Ockhuizen 2003), N|uu (Miller 2010) and G|ui (Nakagawa 2006). Language specific differences exist.

\footnotetext{
${ }^{2}$ In recent studies, the data collection time has been reduced to 20 minutes for 4 takes by saving the files as raw DICOM files.
} 
Table 4 Experimental wordlist with number of ultrasound tokens analyzed

\begin{tabular}{|c|c|c|c|c|}
\hline Participant & $\begin{array}{l}\text { Dental } \\
\text { click type }\end{array}$ & $\begin{array}{l}\text { Alveolar } \\
\text { click type }\end{array}$ & $\begin{array}{c}\text { Palatal } \\
\text { click type }\end{array}$ & $\begin{array}{c}\text { Lateral } \\
\text { click type }\end{array}$ \\
\hline & $\begin{array}{c}\mathrm{g} \mid \mathrm{ai} \\
\text { [o|íí] } \\
\text { 'to exit' }\end{array}$ & $\begin{array}{c}\text { g!ai } \\
\text { [o'!áí] } \\
\text { ‘carry' }\end{array}$ & $\begin{array}{c}\text { łaih } \\
\text { [łifì̀ } \\
\text { 'malaria' }\end{array}$ & 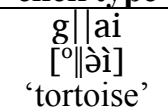 \\
\hline$\overline{\text { JF (Male) }}$ & 8 & 15 & 8 & 15 \\
\hline$\overline{\text { MA (Male) }}$ & 7 & 7 & 3 & 12 \\
\hline$\overline{\text { SR (Female) }}$ & 3 & 3 & 3 & 0 \\
\hline TK (Female) & 3 & 5 & 3 & 6 \\
\hline
\end{tabular}

\subsubsection{LOGIQ e ultrasound machine settings}

A GE LOGIQ e ultrasound machine (software version R4.0.3) with an 8C-RS pediatric curvi-linear probe that scans from 5-8 MHz, was scanning at $8 \mathrm{MHz}$ in the data collected for this study. A $114 \mathrm{fps}$ frame rate was achieved by setting the line density to 2 , and the number of focal zones to one. Additionally, frame averaging was set to 1 , which resulted in minimal temporal smoothing.

The number of radial scan lines in ultrasound machine hardware can be dependent on the line density setting. A line density setting of 2 was used in the current study. Given this line density setting, the number of scan lines used to produce the ultrasound images is 256 lines, according to General Electric engineers (Lee, p.c.). The 114 fps frame rate resulted in each ultrasound frame being $8.77 \mathrm{~ms}$ in duration $(1 / 114)$.

The maximum focal depth was initially set to $8 \mathrm{~cm}$ for all of the recordings, and the focal zone was set at $3.75 \mathrm{~cm}$, but adjustments were made for each speaker to be sure that the entire tongue from root to tip could be seen in the field of view, and that the tongue occupied as much of the field of view as possible. In order to undo the zooming effect caused by adjustment of the focal depth for each speaker, and to accurately represent the data in a way that reflects anatomical differences in tongue size among speakers, the data were scaled to stone palate casts that were made for each speaker using the methodology described in Rudd, Morrow and Bange (1969) and Ladefoged (2003).

Technical Gain Control (TGC) settings were adjusted to avoid amplification of artifacts that are prevalent in the upper pharyngeal region in the production of palatal clicks. The artifacts are due to shadows of the hyoid bone that appear as the hyoid swings up. See Miller, Brugman et al.'s (2009) description of palatal click production in N|uu. Edge enhancement was turned off.

\subsubsection{Head Stabilization}

In order to achieve head position certainty with less than $1 \mathrm{~mm}$ of error, combined head to probe anchoring and head movement correction were used. During data collection, the ultrasound probe was anchored to the speaker's mandible using an Ultrasound Stabilization Headset (Articulate Instruments 2008), which reduces the possibility of separate movement of the head and probe.

\subsection{Ultrasound data processing}

Processing the ultrasound data involves six stages for all of the data, and an additional two stages for the majority of the data. The first stage, involves mixing the three separate data files (lingual ultrasound video, video of head with Palatoglossatron sticks used for head movement correction, and audio files) and 
converting the mixed videos to a series of jpeg images. The second stage, involves identifying frames to trace, and tracing images from swallow recordings for the palate traces, and certain frames of the lingual ultrasound videos of the click consonants using Palatoglossatron software. A third stage involves head movement correction using Palatoglossatron software, and an add-on script called Peterotron. A fourth stage involves conversion of the pixels to centimeters. These four stages of processing are described fully in Miller and Finch (2011). A fifth stage that was developed to compare data from different speakers with different tongue sizes involves scaling the tongue and palate data using scaling factors determined from the ratios of the length and depth of the mid-sagittal palate trace to the length and depth of a stone palate cast that was made for each speaker. The sixth stage involved data translation to shift the data to the first quadrant.

Figure 2 provides an illustration of the five stages of processing for a palate traced from a swallow video, and a single ultrasound image, that was taken within $8.77 \mathrm{~ms}(+/-4.39 \mathrm{~ms})$ of the anterior release in a single production of the palatal click type that was recorded in JF's take 6 (the take that was chosen as having the default probe angle).
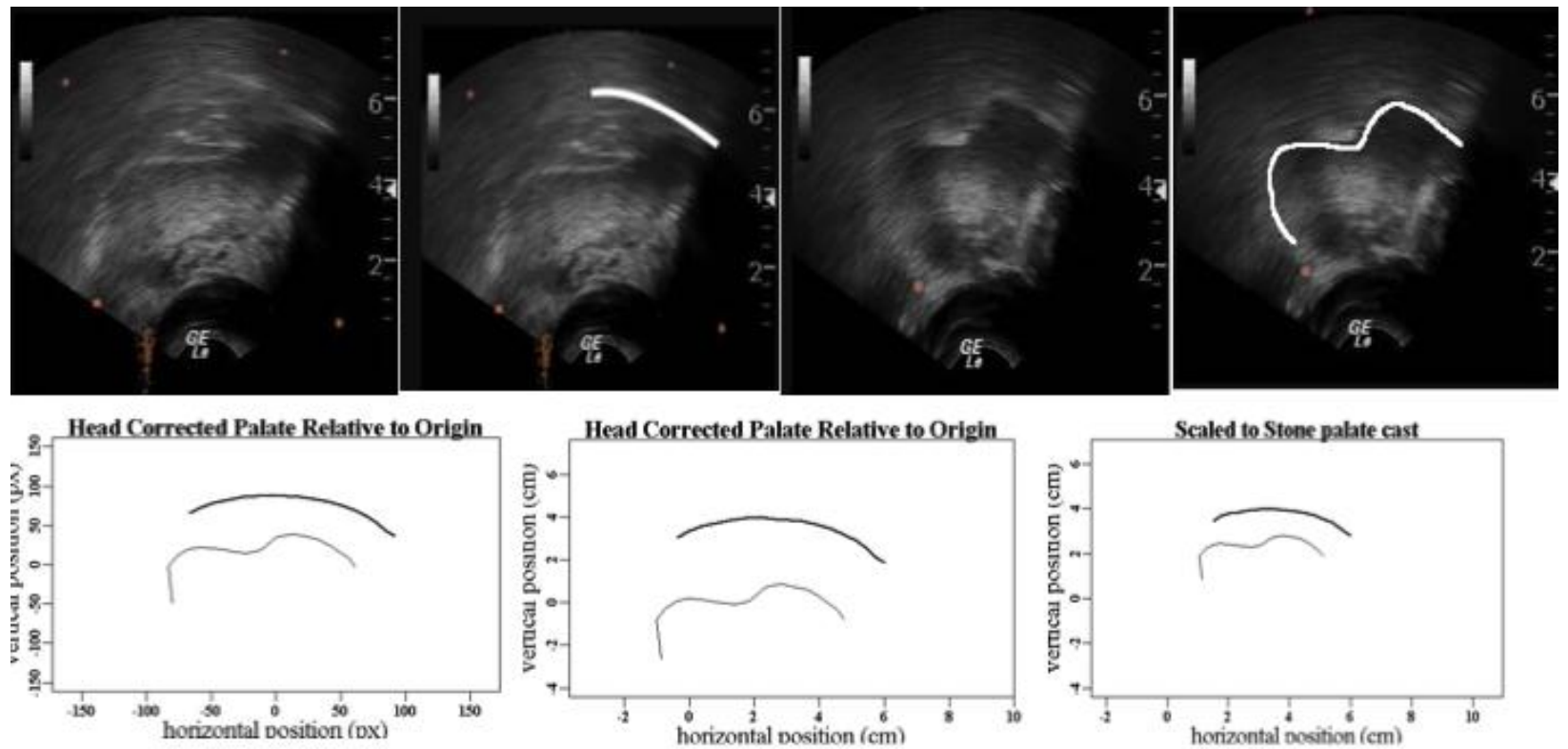

Figure 2. Illustration of 5 Stages of data processing for a palate trace from a swallow video, and the tongue trace that is within $8.77 \mathrm{~ms}$ of the anterior release of a palatal click production recorded in Take 6 for Speaker $J F$, the take that was chosen as the default probe angle for all of the data: Stage 1, untraced palate image chosen from swallow video (upper left) and untraced palatal click trace (2 ${ }^{\text {nd }}$ from upper right); Stage 2, same swallow video frame with traced palate and Palatoglossatron head movement tracking dots ( $2^{\text {nd }}$ from upper right) and same palatal click frame traced with Palatoglossatron tracking dots; Stage 3: Head corrected palate and tongue traces exported out of Palatoglossatron, run through the Peterotron add-on script, and plotted relative to the “origin" defined by Palatoglossatron software (center of ultrasound image, lower left); Stage 4, Same traces converted from pixels to centimeters; Stages 5 \& 6: Palate and tongue traces scaled to speaker JF's stone palate cast, and translated to be in the first quadrant 
A seventh stage of processing involved normalization across headset seatings, by, rotating the data that was recorded in other headset seatings by the difference in the angle of the ultrasound probe relative to the speaker's mandible from the angle used in Take 6. Since this stage followed upon the six stages that were applied to all of the data, this stage is referred to here as stage seven. More detail on how each of the seven stages was completed is provided in Sections 3.2.1 - 3.2.7.

\subsubsection{Alignment and Mixing (Stage 1)}

Manual alignment of the ultrasound and head videos and the audio data followed the procedure outlined in Miller and Finch (2011). The tri-modal 3 ms pulse generator discussed in Miller and Finch (2011) that allows for semi-automatic alignment was not used in the current study. Mixing of the data and conversion to a series of jpegs for further processing is also described in Miller and Finch (2011).

\subsubsection{Palate and Tongue Tracing (Stage 2)}

The hard palate and part of the soft palate were traced in a single frame of a wet swallow image recorded once in each headset seating, following the procedure outlined in Epstein and Stone (2005). As they note, it is the palatine bone that reflects the ultrasound rays, and humans have a mucosa layer below the palatine bone that is thicker on the soft palate than on the hard palate. The presence of a thicker mucosal layer on the soft palate explains the gap seen between the traced tongue images and the traces of the front part of the soft palate in the plots provided in this paper. The gap results in an apparent lack of tonguepalate contact in the back part of the mouth seen in some of the plots. This apparent lack of posterior tongue-palate contact is an illusion.

The reliability of palate traces taken from ultrasound is high. Epstein and Stone (2005: 9) provide results of a pilot experiment showing the differences in palate traces taken from a number of wet swallows for 12 subjects. Eight out of the twelve subjects' individual palate traces showed maximal difference of less than $1 \mathrm{~mm}$, while four of twelve subjects showed differences from 2-5 mm.

\subsubsection{Determining frames of click data to trace}

The tongue edge was traced in six ultrasound frames for each of the click tokens. Abercrombie (1967) describes pulmonic stops as involving a shutting phase, a closure phase, and a release phase. Six frames were traced in each of the clicks, corresponding to particular articulatorily defined landmarks in click production. Only the two frames defined in (4) were measured in the current study.

(4) Two articulatorily-defined landmarks in the production of click consonants

Trace 1: The first frame in the closure phase.

Trace 2: The end of the closure (rarefaction) phase (frame prior to the anterior release).

Ladefoged and Traill (1994) note that the positions of the articulators right before the anterior release of clicks are the ones that determine the acoustic properties of the click bursts. In the analysis of the static constriction locations in the current study, the tongue dorsum and root constriction locations are measured just prior to the anterior release of the click, to determine how the four coronal click types differ from each other articulatorily at the time point that best predicts the acoustic qualities of the bursts. This is Trace 2 as defined in (4). 
The location of the traces that were made for a particular token of the alveolar click initial word [9'áí] 'carry' are illustrated in the waveform of the click and surrounding context provided in Figure 3.

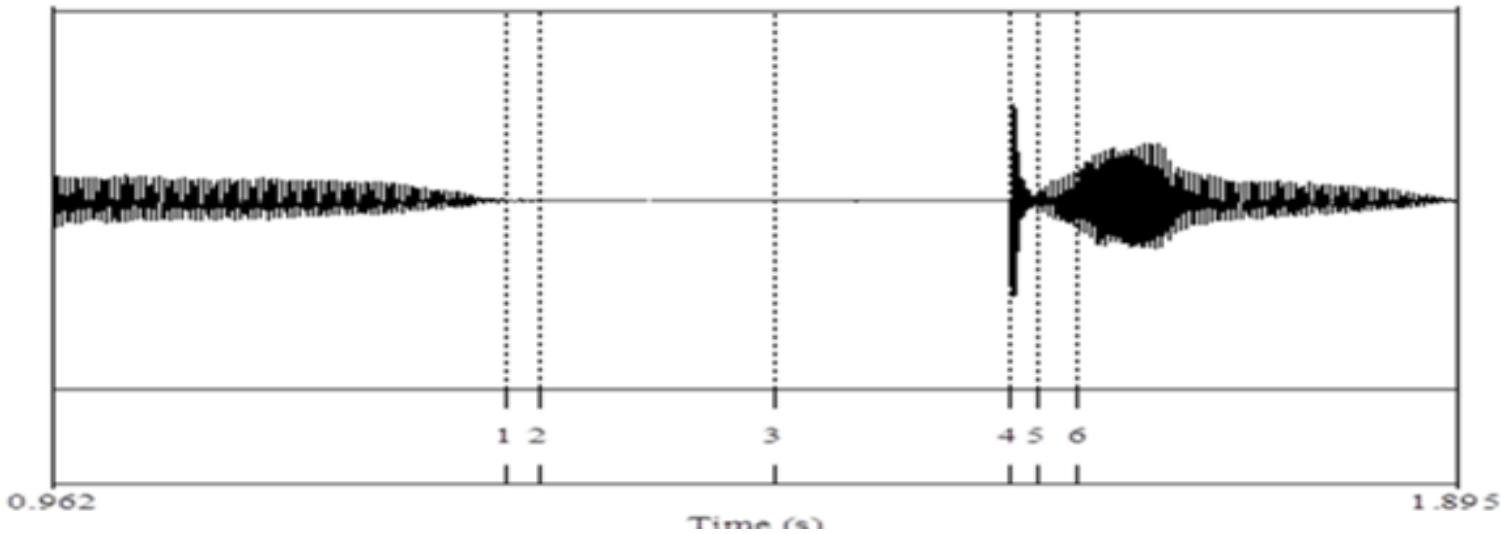

Figure 3 Waveform of the portion of the frame sentence illustrating where the six articulatorily-based landmarks that were used to trace the ultrasound frames in one token of the alveolar click initial word 'g! 'á 'to carry' (JF)

Two ultrasound frames were traced in the velar plosive from the word $k a$ 'it' in the frame sentence. The first frame was identified as the first frame in the closure phase where the tongue dorsum first makes contact with the palate, and the second frame was the frame immediately prior to the dorsal release (end of closure phase).

A non-linguist researcher, who was unaware of the hypotheses being tested, completed the initial traces of the tongue edge in the ultrasound images using Palatoglossatron software. The author and this second researcher checked and verified all of the traces together and agreed upon necessary modifications. Two undergraduate linguistics major research assistants completed a second phase of tracing. The author and these two researchers arrived at the final traces by consensus.

During the posterior release of palatal click consonants, the hyoid, which is attached to the tongue root via the hyoglossus muscle, swings up, and sometimes casts a shadow in the rear part of the ultrasound images. In earlier studies with an older GE Logiqbook machine that could only scan with sufficient image quality of the whole tongue at $30 \mathrm{fps}$, the hyoid shadow at times would obscure part of the tongue root in the ultrasound videos (Miller, Brugman et al. 2009). This was exacerbated by the lower frame rate, the lower image quality that the machine was capable of, and the poorer imaging of the elderly $\mathrm{N} \mid \mathrm{uu}$ speakers that participated in that study. Since N|uu is a much more seriously endangered language (often referred to as moribund) with less than five remaining elders who speak the language, we were unable to pre-test speakers to see how well their tongues imaged. In the current study, there were enough young !Xung speakers available in Mangetti Dune, that we were able to pre-test consultants, and find speakers who imaged well. In addition, the GE Logiq E machine used in this study has superior image quality.

\subsubsection{Image Quality / Ability to trace particular frames}

Eighty five to ninety percent of the lingual ultrasound images were relatively clear, and it was unproblematic to trace the entire tongue edge from root to tip. However, in many ultrasound videos, several frames were difficult to interpret and trace. These were typically frames just prior to the anterior release of the clicks. The lack of clarity in parts of the tongue edge in these frames is likely due to aliasing and other image formation issues, and seem to be related to the extremely high velocity of tongue 
movements as the tongue body pulls down to achieve rarefaction. However, the dynamic movements were recoverable using a method that will be referred to here as Visually Guided Manual Interpolation.

The tongue root position was tracked reliably in this study by moving forward and backwards frame by frame in time in the Palatoglossatron software to determine which of the white lines in the left part of the image is intermediate between preceding and following tongue root positions that are clearer, and make sense as part of a continuous tongue root motion. The white line, which corresponds to the tongue edge, is then traced in the Palatoglossatron software. The extrapolated tongue root position was viewed several times by turning the traced yellow line on and off again in the image, until the researcher was convinced that the line matches what is seen visually in the image. Then, the entire sequence of frames was viewed several more times by stepping forward and backwards frame by frame in time to assure that the motion of the tongue root was continuous and flowing and did not represent any larger than normal jumps in space than could conceivably have occurred within $8.77 \mathrm{~ms}$. This method was followed twice, viewing the tongue front and the tongue dorsum / root separately, as it was challenging to simultaneously identify inconsistencies in the front and back parts of the tongue from frame to frame in a single pass.

Occasionally there was an image that was identified to be traced based on the criteria identified in 3.2.2.1. that did not contain enough visible information to allow accurate tracing of the tongue edge. In such cases, either the preceding or following more visible frame was traced.

\subsubsection{Head Movement Correction (Stage 3)}

Head movement correction of the data was performed using Palatoglossatron (Mielke et al. 2005) software and the Peterotron add-on script, to increase accuracy, and to be able to compare the data from different video takes.

\subsubsection{Conversion from Pixels to centimeters (Stage 4)}

The scale of the ultrasound images recorded in this study was 25 pixels per $\mathrm{cm}$, as measured from Speaker JF's images using the $\mathrm{cm}$ scale that occurs in the ultrasound images following the method described in Mielke et al. (2005). Therefore, the tongue and palate traces were converted from pixels to centimeters by dividing each of the points by 25 . The data analyzed in the current study is thus measured in $\mathrm{cm}$. The difference measures (discussed in section 3.3.2) are multiplied by 10 , so that the fine differences are analyzed and plotted on a millimeter scale.

These seven stages have been successfully applied to hundreds of traces previously (Miller \&Finch 2011). In this study there are approximately 14 traces per token, 10 tokens of each of the 5 syllable types per speaker, and 3 speakers, for a total of 2100 complete tongue traces. These 2100 tongue traces have been experimentally verified by comparison with lingual cavity landmarks and with each other as more fully demonstrated in the supplemental material. In addition, this data is consistent with each other at the initial stage and each subsequent stage.

\subsubsection{Scaling to Stone Palate Casts (Stage 5)}

It was necessary to undo the zooming effect of using speaker-specific focal depth settings that were necessary due to differences in tongue size. In order to accomplish this, the tongue and palate traces were multiplied by an appropriate speaker-specific scaling factor, which was calculated by measuring the length and depth of the average palate in the ultrasound images, and the length and depth of a stone palate cast that was made for each speaker following the method described in Ladefoged (2003). The length of 
each speaker's palate cast was measured using a string placed along the mid-sagittal arc of the palate cast. The palate cast depth was measured from the highest point of the palatal arch to the bottom of the cast. The formulas used to calculate the ultrasound palate length and depth, along with the calculation of the speaker specific scaling factors, are provided in (5).

(5) Formulas for calculation of speaker-specific scaling factors:

- Ultrasound Palate Length = Maximum - minimum horizontal values on traced ultrasound palate

- Ultrasound Palate Depth = Maximum - minimum vertical values on the traced ultrasound palate

- Horizontal Palate Scale = Stone Palate Length / ultrasound Palate Length

- Vertical Palate Scale $=$ Stone Palate Depth / ultrasound Palate Depth

\subsubsection{Normalization across Headset Seatings (Stages 6 \& 7)}

The goal during ultrasound data collection was to keep the ultrasound probe in the same position relative to the speaker's mandible when placing the probe / ultrasound stabilization headset on the speaker's head for each headset seating. This was verified visually during recording by assuring that the mandible shadow occurred in the same position in the ultrasound images as was suggested by Stone (2005). However, after recording, it was evident that the angle of the ultrasound probe relative to the speaker's mandible varied slightly in the different seatings of the probe / headset.

To normalize the data so that it was all in the same perspective, the angle of the ultrasound probe relative to the mandible was estimated from the mandible shadow that occurs in the right edge of every ultrasound image. The mandible shadow angle was estimated by placing two dots on the palate image taken from the swallow recording that was recorded in each headset seating with Palatoglossatron software. Figure 4 provides an example of a swallow image from a single take. The dot labeled A was placed at the center of the ultrasound image, which was carefully measured to be equidistant from the upper and lower edges, and the right and left edges of the image. The dot labeled B was placed at the intersection of the upper edge of the ultrasound image arc with the left edge of the mandible shadow. An R script was developed that measured the angle of line $\mathrm{Z}$, which runs between points $\mathrm{A}$ and $\mathrm{B}$ for each of the takes, and this angle was used as an estimate of the angle of the probe relative to the mandible.

The probe angle in one ultrasound recording of a swallow was chosen as the standard probe angle based on visual inspection of the data to determine the most upright position of the participant's head among the recordings (JF, Take 6). The palate traces from each headset seating were then rotated by the difference of the angle of line $\mathrm{Z}$ between the most upright palate trace (JF Take 6) and the palate trace from the particular headset seating. The dots in the squares in the image in Figure 4 are the head and probe tracking dots that were mounted on the rods placed on a pair of glasses worn by the subject and on the ultrasound probe. 


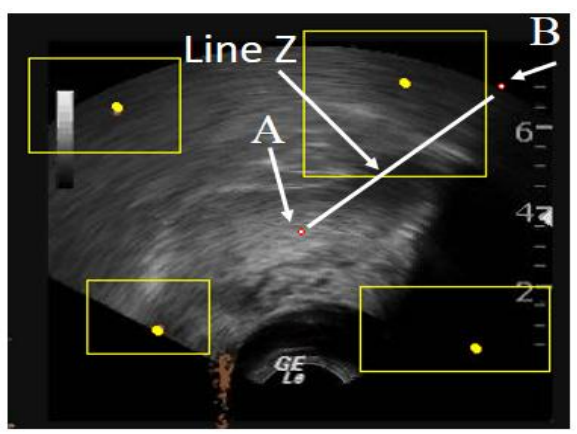

Figure 4 A single ultrasound image from a single frame of a swallow produced by JF with two pink dots placed on (A) the center of the image; and (B) the intersection of the outer arc of the ultrasound scan with the left edge of the mandible shadow, and $(Z)$ a line drawn between points $A$ and $B$

Figure 5 provides multiple images of a single frame taken from a number of tokens of the alveolar click type. These frames were identified to be the frame just before (within $8.77 \mathrm{~ms}$ of) the anterior release of the click (Trace 4) recorded in each of the eight takes recorded in this study (images are marked with the speaker's initials and take number). There were four takes recorded for speaker JF, two for speaker MA, and one for speaker TK. As noted above, the number of takes of the wordlist that were recorded per probe / headset seating varied due to differences in speaker comfort with the headset placement and the number of technical and human error collection problems that were encountered during the recording of the take.

A critical assumption made here is that since the probe was locked into position by the Ultrasound Stabilization Headset for the duration of each take, the probe angle remained relatively constant throughout each take. This assumption is shown to be correct by viewing the images of similar frames within a take. The upper left image and the image just to the right of this image in Figure 5, are images from two different repetitions of the word [" ${ }^{9}$ ái] recorded in the same take (Take 6) for speaker JF. These two images illustrate that the mandible shadow stayed relatively constant in position throughout the take.

An R script (R Development Core Team, 2011) was developed to rotate all of the tongue traces recorded in each headset seating by the same angle as the palate trace recorded in that take, to assure that all of the data was transformed to the same perspective. This was necessary because the Palatoglossatron software centers in the middle of the US image, which results in half of the x,y points being in quadrants 3 and 4 . The R script also translated the tongue and palate traces by subtracting the maximum vertical positions of all of the palates from the most upright palate and tongue traces. This shifted the lowest position of the yaxis to zero. In order to maintain the front of the palate on the right side of the image, and to keep the $\mathrm{x}$ axis fully within the first quadrant, $10 \mathrm{~cm}$ were added to the right edge of the palate. This resulted in the front edge of each of the palates occurring consistently at $6 \mathrm{~cm}$ on the $\mathrm{x}$-axis for all of the data.

The goal, during data collection, was to lock in the probe position for an entire take. However, sometimes a speaker became uncomfortable in the middle of a take, and asked to have the ultrasound probe lowered. Lowering was undertaken to achieve comfort with the least possible movement. Because of these minor adjustments made within a few of the takes, some of the tongue data had to be translated by a few millimeters to fit the tongue data to the palate data, using an interactive $\mathrm{R}$ script. 


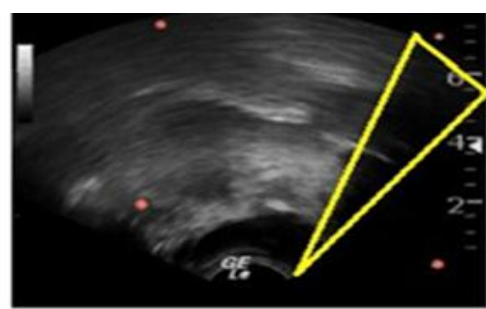

JF Take 6 (Repetition 1)

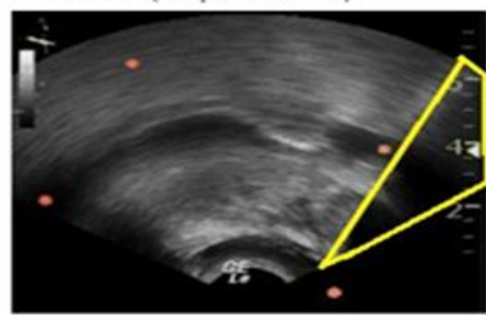

JF Take 10

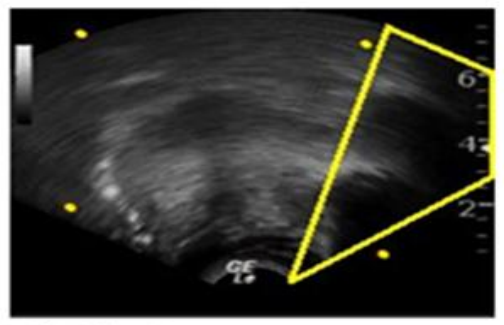

MA Take 5

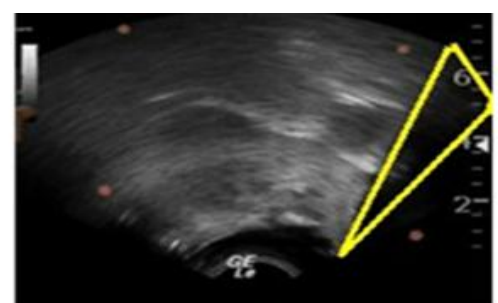

JF Take 6 (Repetition 2)

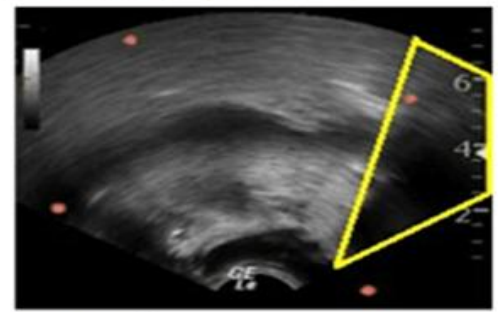

JF Take 12

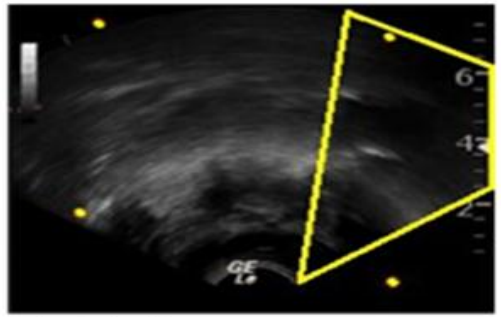

MA Take 8

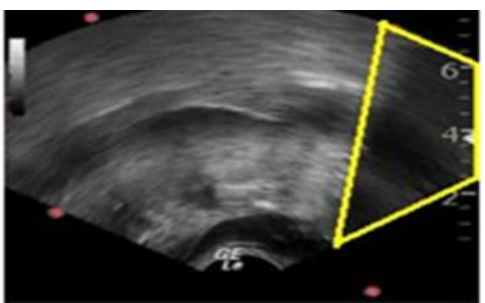

JF Take 9

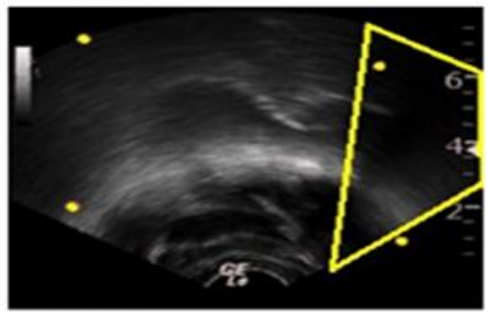

TK Take 3

Figure 5 Ultrasound frames taken just prior to the anterior release of the alveolar click type for all three speakers in the seven different takes recorded in this study, as well as two repetitions from a single take recorded by speaker JF (Take 6). Triangles enclose the mandible shadow in each image.

Palates from each take were aligned and plotted together using an interactive $\mathrm{R}$ script. Differences in the horizontal and vertical location of the peak of the palatal dome were determined via simple subtraction, and recorded. These vertical and horizontal differences in the palate traces were then used to translate the tongue data, so that all of the tongue data was on the same $x-y$ plane.

The formulas used to rotate the angle of the tongue traces, and to translate the data to the first quadrant, are provided in (6). Theta corresponds to the difference in the angle of the mandible shadow in the palate image in a particular take relative to the angle of the mandible shadow in the palate image of JF Take 6, which was chosen as the default angle. 
(6) Formulas used to rotate the palate and tongue data

- Tongue trace horizontal value $=$ Tongue trace horizontal value - horizontal value at center of image

- Tongue trace vertical value $=$ Vertical value at center of image - tongue trace vertical value

- $\quad$ Tongue trace horizontal value $=$ Tongue trace horizontal value $* \cos ($ theta $)$ -

Tongue trace vertical value $* \sin ($ theta)

- Tongue trace vertical value $=$ Tongue trace horizontal value $* \sin ($ theta $)+$

Tongue trace vertical value $* \cos ($ theta)

- Tongue trace horizontal value $=$ maximum horizontal value of palate -

Tongue trace horizontal value

- Tongue trace horizontal value $=10$ - Tongue trace horizontal value

- Tongue trace vertical value $=\quad($ maximum vertical value of palate -

Tongue trace vertical value) +3

\subsection{Ultrasound Data Analysis}

\subsubsection{Static Measurements}

An interactive $\mathrm{R}$ script was developed to take four measurements automatically from each of the five ultrasound tongue traces for each of the repetitions of each click type, and plot them on the tongue trace to check for measurement errors. In most of the productions of the palatal click type, especially those produced by Speaker MA, there is a general upward slope of the tongue from the root to the tip, as there is in the tongue trace in JF's production in Figures 1 and 6 . This led to a large number of measurement errors for this click type. The errors were identified while running the interactive measurement script, and hand-measurements were made at the same time for the problematic tokens to replace the measurement errors. Approximately $15 \%$ of the data required hand measurements to be taken, and the errors were almost solely confined to frames taken from the palatal click type.

The measurement locations are listed in (7), and illustrated in Figure 6. The measurements consisted of two horizontal measurements that represent the tongue dorsum constriction location, and the farthest back tongue root position; and two vertical positions of the Tongue Dorsum and Tongue Root.

Tongue Dorsum (TD) constriction locations were identified from turning points in the horizontal (x) values of each tongue trace. The $\mathrm{R}$ script started searching from the left edge of the tongue trace (i.e. the smallest $\mathrm{x}$ value) to identify the first turning point on the vertical plane, which was always a local vertical (y-value) maximum. This first turning point was taken to represent the Tongue Dorsum constriction location. Both the $\mathrm{x}$ and $\mathrm{y}$ values for this first turning point were recorded. The tongue root position did not correspond to a clear constriction in many cases, and thus it was measured a bit differently. Additionally, the tongue root is vertical when a person is seated upright, as the speakers in this study were during recording. The Tongue Root position was identified as the lowest horizontal value, which represents the farthest back Tongue Root position. The horizontal and vertical locations of the farthest back Tongue Root position were recorded. 
(7) Four Measurements taken on each of the Six Tongue Traces

a. Horizontal position of the Tongue Dorsum (Tongue Dorsum Constriction Location, TD CL);

b. Horizontal position of the Tongue Root (Tongue Root Constriction Location, TRCL);

c. Vertical position of the Tongue Dorsum Constriction;

d. Vertical position of the farthest back TR position.

\subsubsection{Dynamic Measurements / Analysis of Rarefaction Gestures}

The analysis of lingual rarefaction gestures in the four click types in Mangetti Dune !Xung is undertaken to investigate whether the alveolar and lateral click types involve Tongue Dorsum and /or Tongue Root retraction during the closure phase that are not exhibited in the dental and palatal click types (Q3). In order to test hypothesis H3, movement in the horizontal positions of the Tongue Dorsum and Tongue Root are calculated by subtracting the Tongue Dorsum and Tongue Root horizontal locations at T2, which is within $8.77 \mathrm{~ms}$ of the anterior release, from T1, which is at the beginning of the closure phase. Figure 6 provides an illustration of how the Tongue Dorsum and Tongue Root locations are identified in Traces 1 and 2 of a single token each of the alveolar and palatal click types. Measurements are provided in Table 5, which show that the TDCL retracts substantially in both the alveolar and palatal click types, while the Tongue Root advances slightly in both of these tokens. The height of the TD and TR constrictions are also measured, since the vertical position of the Tongue Root Constriction seems to differ between the alveolar and dental clicks, when compared with the palatal click. 
Alveolar Click Initial [g!éi] 'to carry'

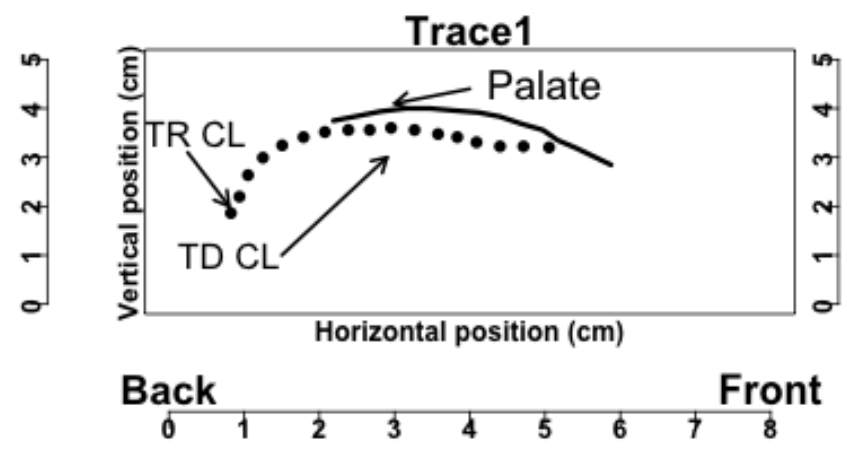

Trace 2

$m$
+
0
0

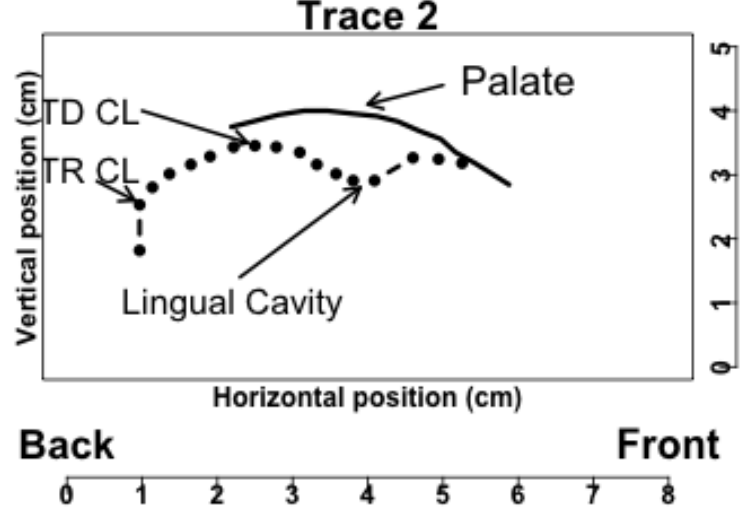

Palatal Click Initial [₹inì] 'malaria'
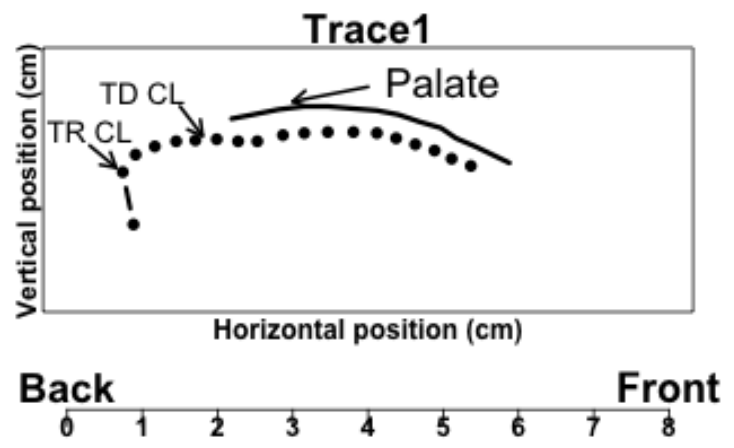

Trace 2

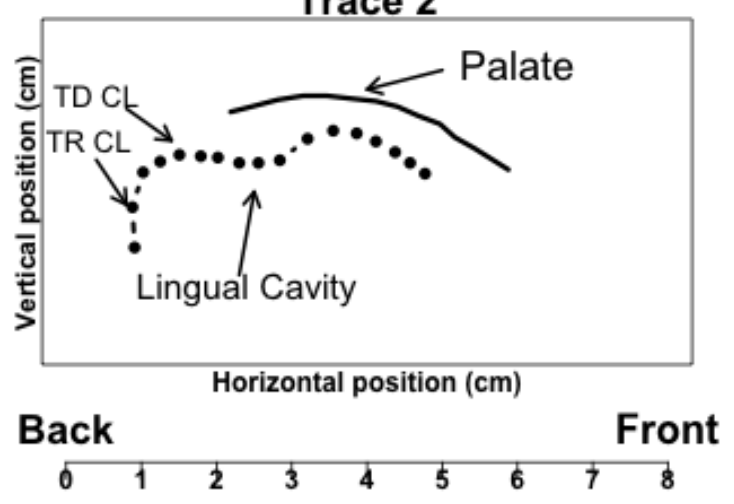

Figure 6 Example of a single tongue trace just before the anterior release (Trace 4) in a single token of a palatal click type (left), and a single token of an alveolar click type (right), with the four constriction locations marked on the tongue traces (Speaker JF)

Table 5 Tongue Dorsum and Tongue Root Constriction Location Measurements for Traces 1 and 2 as well as the rarefaction measurements (T1-T2) of a single token of the palatal click type illustrated in Figure 7

\begin{tabular}{llccc}
\hline Click Type & $\begin{array}{l}\text { Constriction } \\
\text { Location }\end{array}$ & Trace 1 $(\mathbf{c m})$ & Trace 2 $(\mathbf{c m})$ & $\begin{array}{l}\text { Rarefaction Gestures } \\
\text { (T1-T2, cm) }\end{array}$ \\
\hline Alveolar [!] & Tongue Dorsum CL & 2.95 & 2.50 & $0.45(45 \mathrm{~mm})$ \\
\hline & Tongue Root CL & 0.82 & 0.96 & $-0.14(14 \mathrm{~mm})$ \\
\hline Palatal [=] & Tongue Dorsum CL & 1.99 & 1.51 & $0.48(48 \mathrm{~mm})$ \\
\hline & Tongue Root CL & 0.74 & 0.88 & $-0.14(-14 \mathrm{~mm})$ \\
\hline
\end{tabular}




\subsection{Error}

\subsubsection{Spatial Error}

The ultrasound machine image size was inadvertently set to smaller than maximum in this study, yielding a lower resolution than was achieved in Miller and Finch's (2011) study. Instead of the 6 pixels / mm achieved in that study, the ultrasound images in the current study have 2.5 pixels per $\mathrm{mm}$. It was possible to trace to within a pixel or two. However, the lower resolution increased the tracing error from the 0.17 $0.33 \mathrm{~mm}$ reported in the earlier study, to $0.4-0.8 \mathrm{~mm}$ in this study. The expectation is that when the other types of error, such as tongue tracing error are added, there is still $<1 \mathrm{~mm}$ of spatial error overall.

\subsubsection{Temporal Error}

Temporal error is half of a frame rate. Given the $114 \mathrm{fps}$ frame rate used in the current study, the temporal error is half of one frame, $8.77 \mathrm{~ms} / 2=4.4 \mathrm{~ms}$.

\subsection{Statistical Treatment}

Means and standard deviations were calculated for each measurement for each consonant type. The means of the individual constriction locations and heights at the T1 and T2 landmarks, as well as the differences between these constriction locations and heights at T1-T2 are provided in the appendix. Boxplots of the dynamic measurements that were significantly different for all of the speakers are provided in Section 4.

Regression models using the R Statistics function glm modeled after Hastie and Pregibon (1992) were created for each of the measurements. Individual models were created for each of the speakers: JF, MA and TK. Two independent variables were considered to be possible determinants of the tongue dorsum constriction locations and heights. The variable Palatal vs. Pre-palatal, was coded as to whether the front constriction locations in the clicks were palatal, or pre-palatal, as in the dental, alveolar and lateral click types. The Palatal value was defined as the reference value. Vowel Context was coded as a three-level factor, distinguishing between [a], [əi] and [i]. The [əi] context was defined as the reference level. The variables were regressed in separate models against all four dependent measurements listed above in (5)(a)-(d) as well as the dynamic measurements of Tongue Dorsum and Tongue Root retraction.

The regressions that used Vowel Context as a factor addressed Q2, and tested Hypothesis H2a. The Palatal vs. Pre-palatal variable regression addressed Hypothesis H2b. The same variables were used to investigate the independent variables that affected the TD and TR movement as rarefaction gestures.

There were four distinct syllable types in the regressions that compared just the clicks, and five that included the $k a$ syllable type. Thus, the regressions that undertook pairwise comparisons had either three or four degrees of freedom. The alpha value is $\mathrm{p}<.05$. Statistical tables provide an asterisk marking significant comparisons where the $\operatorname{Pr}(>/ t /)$ value is less than the alpha value. Regressions that showed similar significant patterns for all three speakers are included in the paper.

Measured differences between syllable types must be evaluated given the error rate of $<1 \mathrm{~mm}$. Thus, differences of less than $1 \mathrm{~mm}$, even if significant, must be discounted.

Regression Results are provided in Appendix A. 


\subsection{Results}

Section 4.1. provides the lingual ultrasound traces of all tokens of the four click types at T1 and T2 and describes differences in constriction location, height, and overall tongue shapes between the different click types. This section provides the data needed to answer Q1 and determine if the "flat vs. concave tongue shape" hypothesis is supported. The measurement results of the Tongue Dorsum constriction locations and heights are provided in Section 4.2, and the measurement results of the Tongue Root constriction locations and heights are provided in Section 4.3. These results provide the answer to the second research question (Q2), which asks about the posterior lingual constriction locations, and will aid in determining whether H2a, the "Vowel Context hypothesis", or H2b, the "Front Constriction Locations predict back constriction locations" hypothesis is best supported by the data. The measurement results of the rarefaction gestures that involve kinematics of the Tongue Dorsum and Root during the closure phase of the clicks are provided in Section 4.4. This data is needed to answer Q3, which is about differences in posterior tongue movements involved in rarefaction. They are provided to help determine whether H3a, the "Tongue Root Retraction vs. Tongue Bunching Hypothesis" or H3b, the "Tongue tip retraction conditions Tongue Dorsum / Root Retraction" hypothesis is supported.

\subsection{Constriction Locations and Overall Tongue Shapes}

Figure 7a provides plots that contain all of the tongue traces at the two articulatory defined landmarks (T1 and T2) for of each of the four click types produced by Speaker JF. Trace 1 is the first frame where both constrictions are in place (beginning of the closure phase), and Trace 2 is the frame just before the release of the anterior constriction (end of the closure phase). Similar plots of the four click types produced by the other two speakers (MA and TK) are provided as Figures $7 \mathrm{~b}$ and $7 \mathrm{c}$. These plots show that the dispersion of the individual tongue traces taken at each of the two landmarks in each of the four coronal click types is rather narrow. In each of the click types within each speaker's productions, the tongue front and tongue dorsum constriction locations are fairly consistent. However, there is variation among two of the speaker's productions of the palatal click type, and a third speaker seems to produce two distinct variants. Each click type is discussed individually.

\subsubsection{Dental Click Type}

In Speaker JF's productions of the dental click type, in T1 the tongue shape is fairly flat. In this speaker's productions, T2 displays two rather broad constrictions, with the anterior constriction appearing to be apico-laminal. The lingual cavity is rather shallow compared to the other three click types. In Speaker MA's productions of this click type, the two constriction peaks and the lingual cavity well between the two constrictions are already visible at $\mathrm{T} 1$. The cavity deepens slightly by the end of the rarefaction phase (T2). Speakers TK's productions are more similar to JF's, in that the anterior constriction seems to be a broad apico-laminal constriction. However, her productions differ from JF's productions, and are more similar to MA's productions, in that the lingual cavity well is already visible at the beginning of the closure phase (T1). She deepens the lingual cavity substantially by the end of the closure / rarefaction phase. 
Dental Click [glíí] 'to exit'

Trace 1

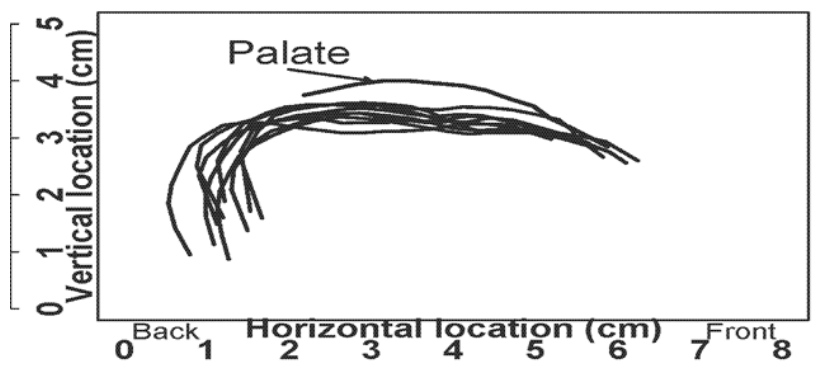

Trace 4

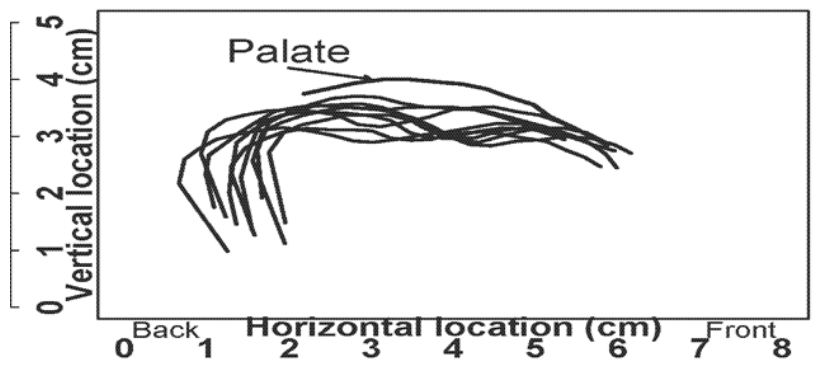

Lateral Click [gllə̀i] 'tortoise'

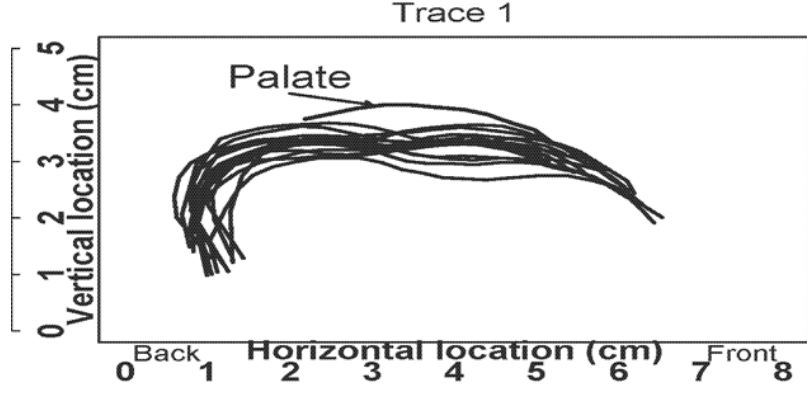

Trace 4

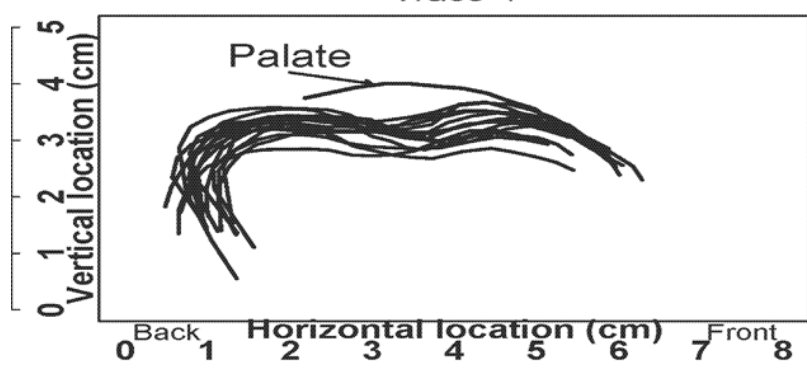

Alveolar Click [g!éí] 'to carry' Trace 1

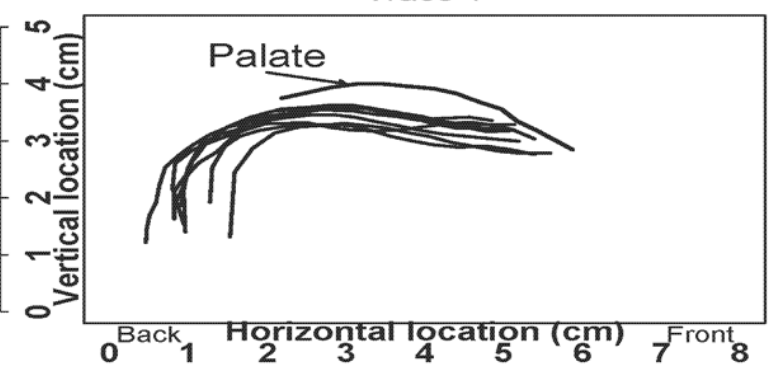

Trace 4

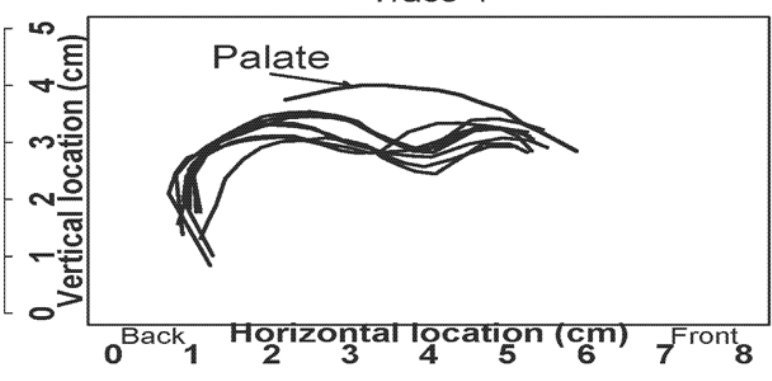

Palatal Click [₹ihì] 'malaria' Trace 1

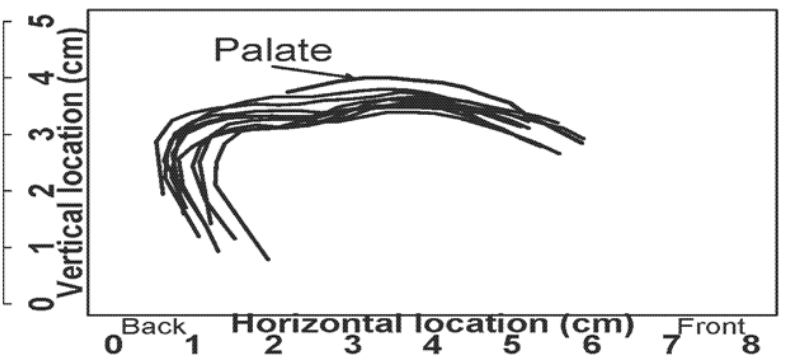

Trace 4

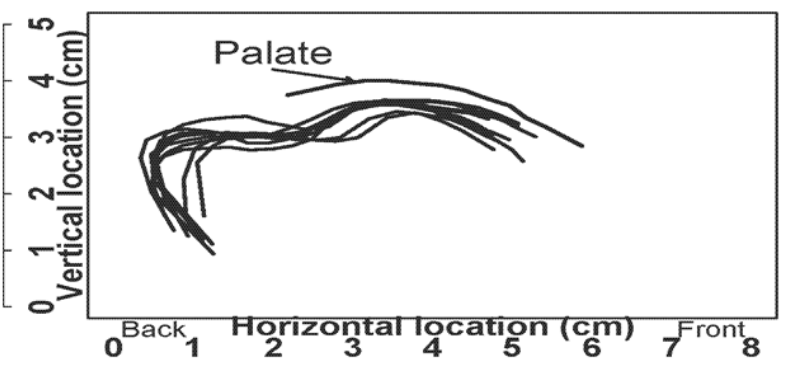

Figure 7a All tokens of Trace 1 and Trace 2 of Speaker JF's productions of the four contrastive coronal click types in Mangetti Dune !Xung 
Dental Click [glíí] 'to exit' Trace 1

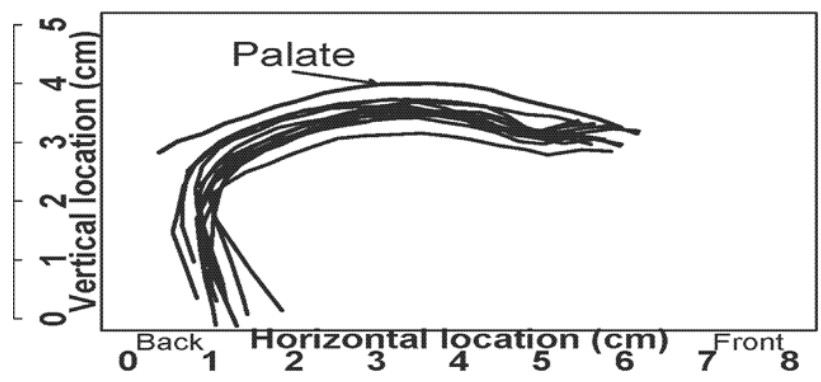

Trace 4

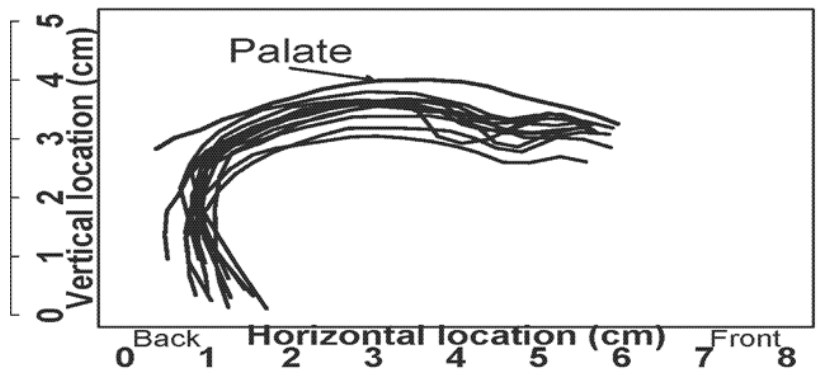

Lateral Click [gllèi] 'tortoise' Trace 1

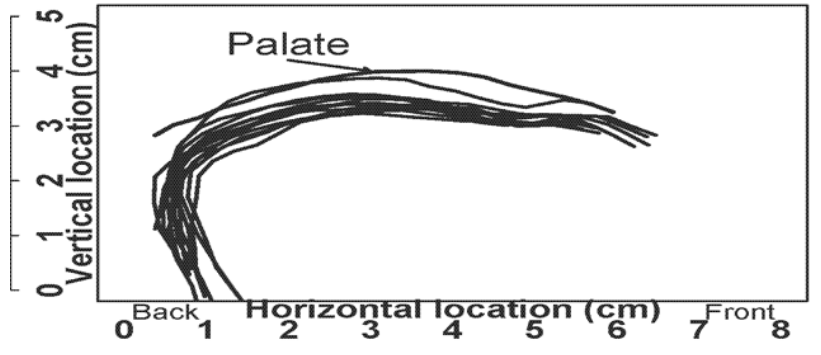

Trace 4

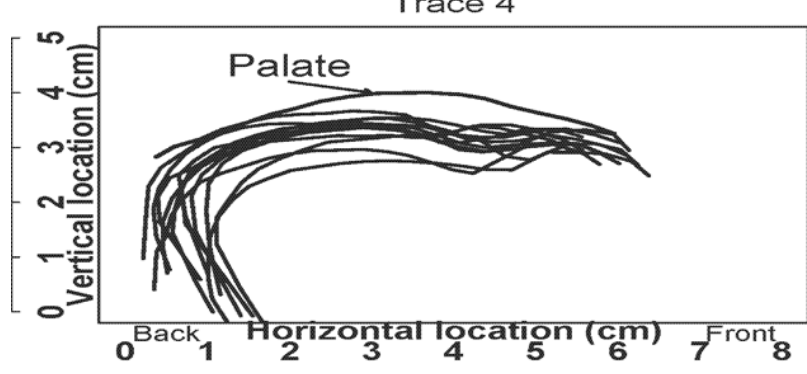

Alveolar Click [g!éí] 'to carry' Trace 1

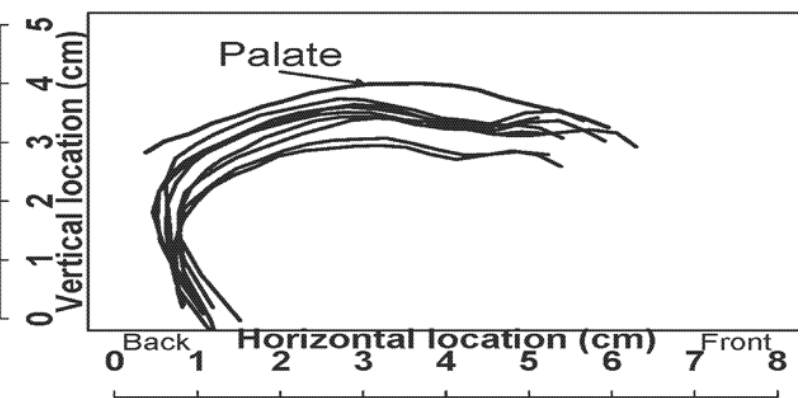

Trace 4

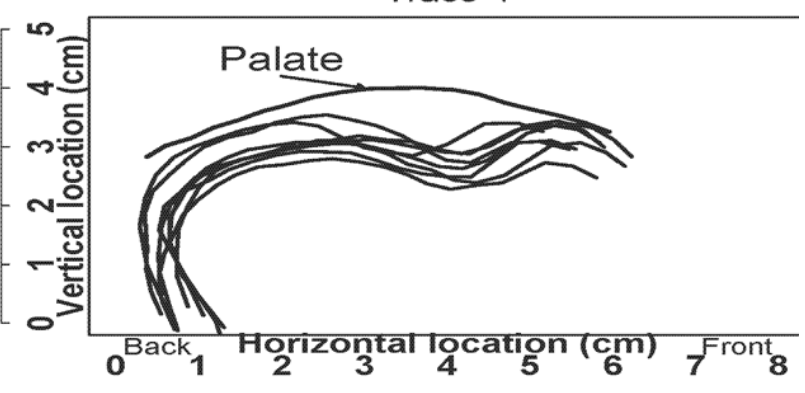

Palatal Click [₹ihì] 'malaria' Trace 1

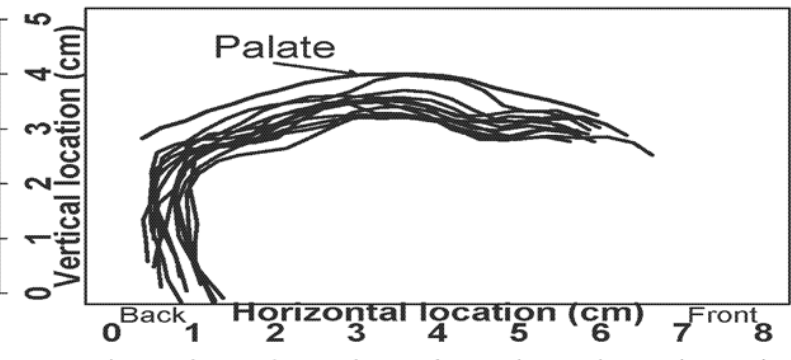

Trace 4

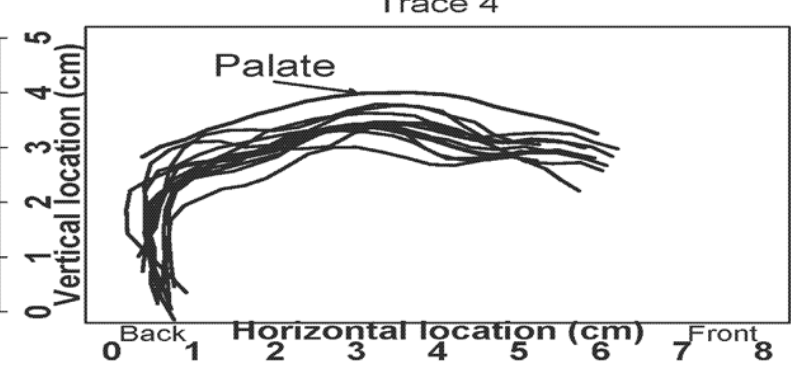

Figure $7 \mathrm{~b}$ All tokens of Trace 1 and Trace 2 of Speaker MA's productions of the four contrastive coronal click types in Mangetti Dune !Xung 
Dental Click [glíí] 'to exit'

Trace 1
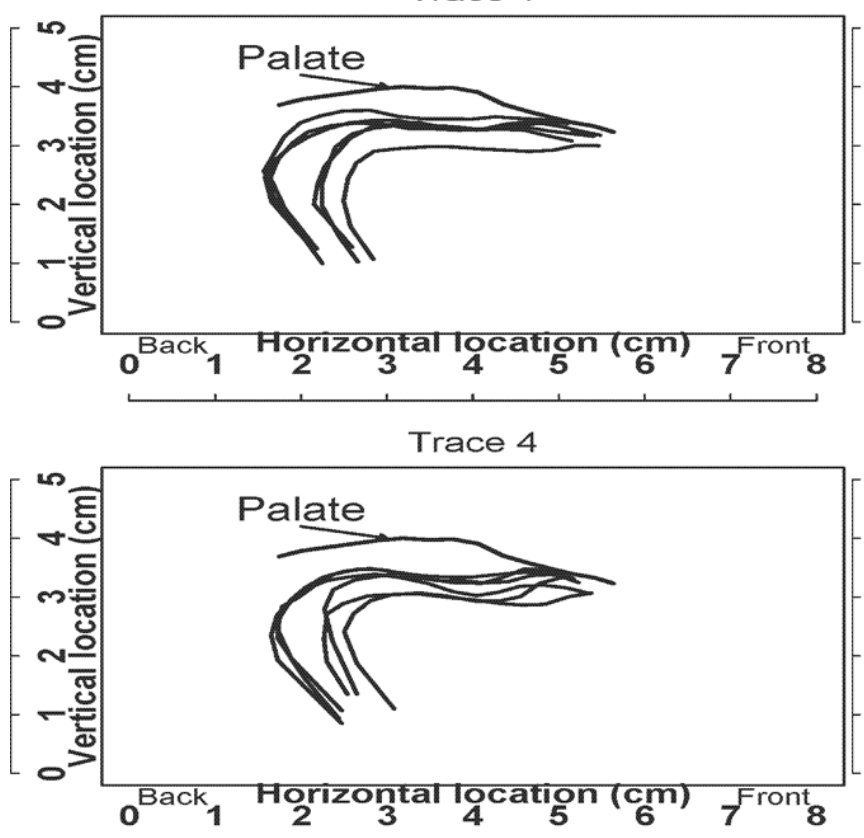

Lateral Click [gllə̀i] 'tortoise' Trace 1

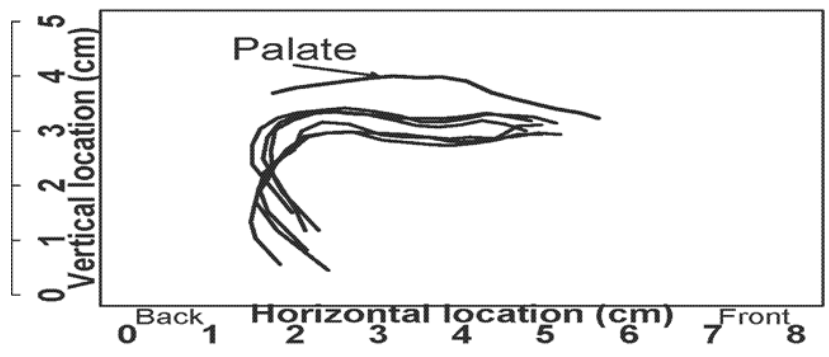

Trace 4

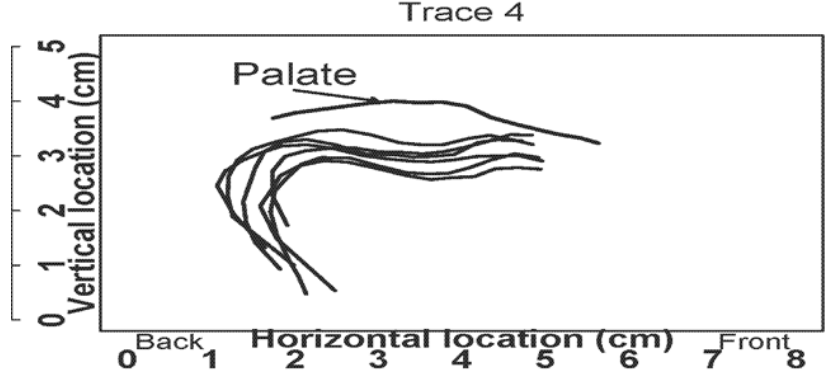

Alveolar Click [g!éí] 'to carry' Trace 1
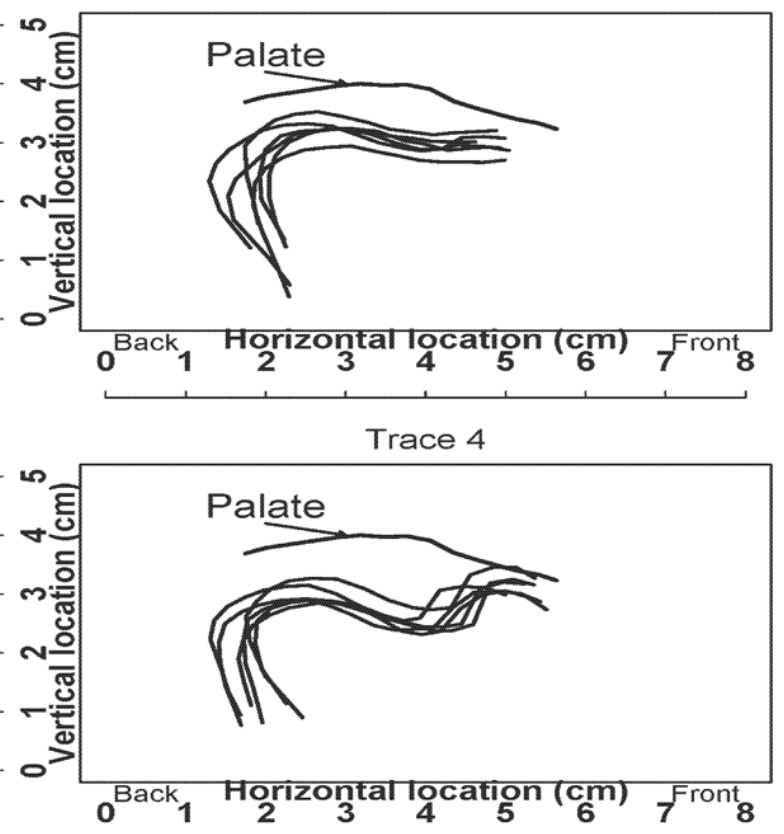

Palatal Click [₹ihì] 'malaria' Trace 1
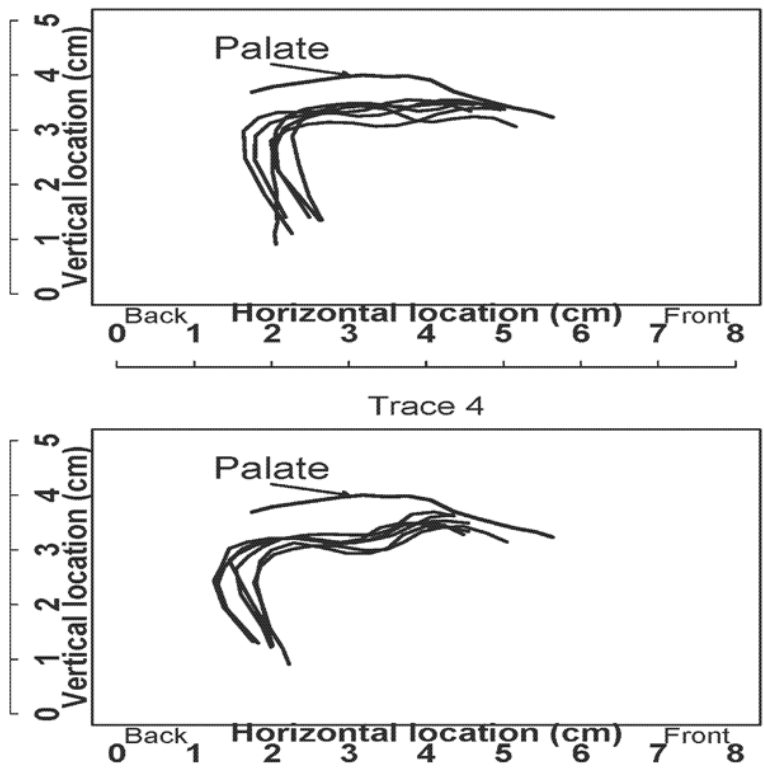

Figure 7c All tokens of Trace 1 and Trace 2 of Speaker TK's productions of the four contrastive coronal click types in Mangetti Dune !Xung

The flat tongue shapes seen for JF's and TK's productions of the dental click type provide support for H1, the "flat vs. concave tongue shape hypothesis. MA's productions are not quite as flat as seen for these other two speakers. The lingual cavity size seems to be consistent across the three speaker's productions. However, MA's productions show a shorter slightly deeper lingual cavity, compared to JF's and TK's 
productions, which have longer shallower lingual cavities. Thus, it appears that lingual cavity volume may be held more consistent than tongue shape. This might be a better predictor of the spectral properties of the click burst.

\subsubsection{Alveolar Click Type}

The alveolar click type contains a narrow apical front constriction that is produced by the tongue tip making contact with the alveolar ridge or post-alveolar region in all speakers' productions. The underside of the tongue tip was often visible in the ultrasound videos, and the front edge of the underside of the tongue is traced in most of MA's productions. This constriction shape differs from the broader more laminal front constrictions seen in the productions of the dental click type. The dorsal constriction in this click type is similar in constriction location and shape to the constriction seen in the dental click type. The farthest back tongue root position in this click type occurs in the mid oro-pharyngeal region, about the same location as the one that occurs the dental click. The tongue body shape is concave, providing support for the "flat vs. concave tongue shape" hypothesis (H1).

\subsubsection{Lateral Click Type}

The lateral click type, exhibits tongue dorsum and tongue root constrictions that are very similar to those found in the dental and alveolar click types. The tongue body lowering apparent on the mid-sagittal plane in this click type is rather minimal. This is likely because the greatest degree of tongue body lowering occurs in the lateral margins.

The tongue dorsum constriction locations in the lateral click productions are quite similar to those found in the alveolar click type for two of the speakers. However, the tongue dorsum seems to be further back in the lateral click type than in the alveolar click type for speaker TK. It is important to note that the ultrasound data presented here are all taken on the mid-sagittal plane. Coronal or 3D ultrasound data would be useful to determine the position of the largest tongue dorsum and tongue root movements in the lateral click type.

The lingual cavity depth seen in the mid-sagittal plane is more minimal in all speakers' productions of the lateral click type than in the alveolar click type productions, and the tongue shape (and lingual cavity size) seems to be intermediate between the more flat dental click type and the more concave alveolar click type. The intermediate tongue shape and cavity size does not provide clear support for or against the "flat vs. concave tongue shape hypothesis."

\subsubsection{Palatal Click Type}

The palatal click type differs from the other three click types in terms of the posterior constrictions. The tongue dorsum constriction location in the palatal click type is farther back and lower than that found in the other three click types. This is, like the dental click type, in spite of the fact that the following vowel in the word used in this study, and the preceding word in the frame sentence, are both non-low front vowels. The dental and palatal click types are quite different from each other.

The tongue dorsum constriction in this click type is relatively narrow compared with those found in the other three click types. The tongue front constriction location also seems rather narrow, compared with the other clicks. The narrower constriction peaks are likely due to the fact that the front constriction is farther back in this click type, leaving a smaller space to produce a lingual cavity, as well as a second, 
dorsal constriction. The tongue dorsum constriction in the palatal click type is higher than that of the other three click types for Speakers JF and TK, but lower for speaker MA. This provides evidence that the velum must also be lower in this click type in MA's productions; since it is necessary for both the coronal and dorsal constrictions to be complete in order to produce a click consonant. The farthest back tongue root position in the palatal click type is also further back for Speaker JF, but not necessarily for the other two speakers. The height of the farthest back point of the tongue in JF's productions is also higher in the mouth in this click type compared with the other three click types. That is, it occurs in the upper pharynx, between the oro-pharynx and the naso-pharynx. The tongue root can be seen raising and bunching in the ultrasound videos of Speaker JF's productions of this click type that are provided in the supplemental material. Thus, we can conclude that the farthest back part of the tongue seen in JF's production in Figure $8 \mathrm{a}$ is the tongue root. However, even though the tongue root constriction is equally far back for this click type compared with the other three click types, it still differs quite greatly from these other click types, in that the tongue root position is raised and bunched, and is not in the lower to mid pharynx where it retracts in the other three click types.

The overall tongue shape is not flat in JF's and TK's productions of the palatal click type. It is much more concave than the flatter shape found in the dental click type. Thus, these speakers' productions of the palatal click type provide evidence against the "flat vs. concave tongue shape hypothesis." Speaker MA's productions of the palatal click display three constrictions, with the third constriction being an additional dental constriction. Previous linguographic and palatographic evidence has led previous researchers to claim that there is a long anterior apico-laminal constriction in the palatal click type that covers a relatively large area. However, the ultrasound results seen here for Mangetti Dune !Xung palatal clicks, suggest that there can be either a single apico-laminal constriction, as in JF's, and TK's productions, or two separate anterior constrictions - a dental constriction, as well as a palatal constriction, as is seen in every one of MA's production of this click type. In MA's productions, it appears that two smaller cavities may be being formed simultaneously - one between the dental and palatal constrictions, and the true lingual cavity that rarefies the air to produce the lingual airstream source, formed between the palatal and uvulo-pharyngeal constrictions in the upper pharyngeal region. Speaker MA produces three constrictions in his productions of the palatal click type. The acoustic consequences of the additional dental constriction, and the additional front cavity that it forms at the front edge of the lingual cavity, are currently unknown.

Speaker TK produces two distinct variants of the palatal click type. Dynamic tongue graphs providing a tongue trace at the beginning of the closure (T1), and a tongue trace just before the anterior release (T2), of these two variant productions are provided in Figure 8. In the production shown in the left panel of Figure 8, we can see that the tongue dorsum and root retract, and there is minimal tongue body lowering. In the production shown in the right panel of Figure 8, the tongue dorsum and tongue root remain static during rarefaction, but there is a much greater degree of tongue body lowering. Thus, it appears that one of the variants that she produces involves more tongue dorsum / root retraction to rarefy the air in the lingual cavity, while the other variant involves more tongue body lowering to achieve rarefaction. 

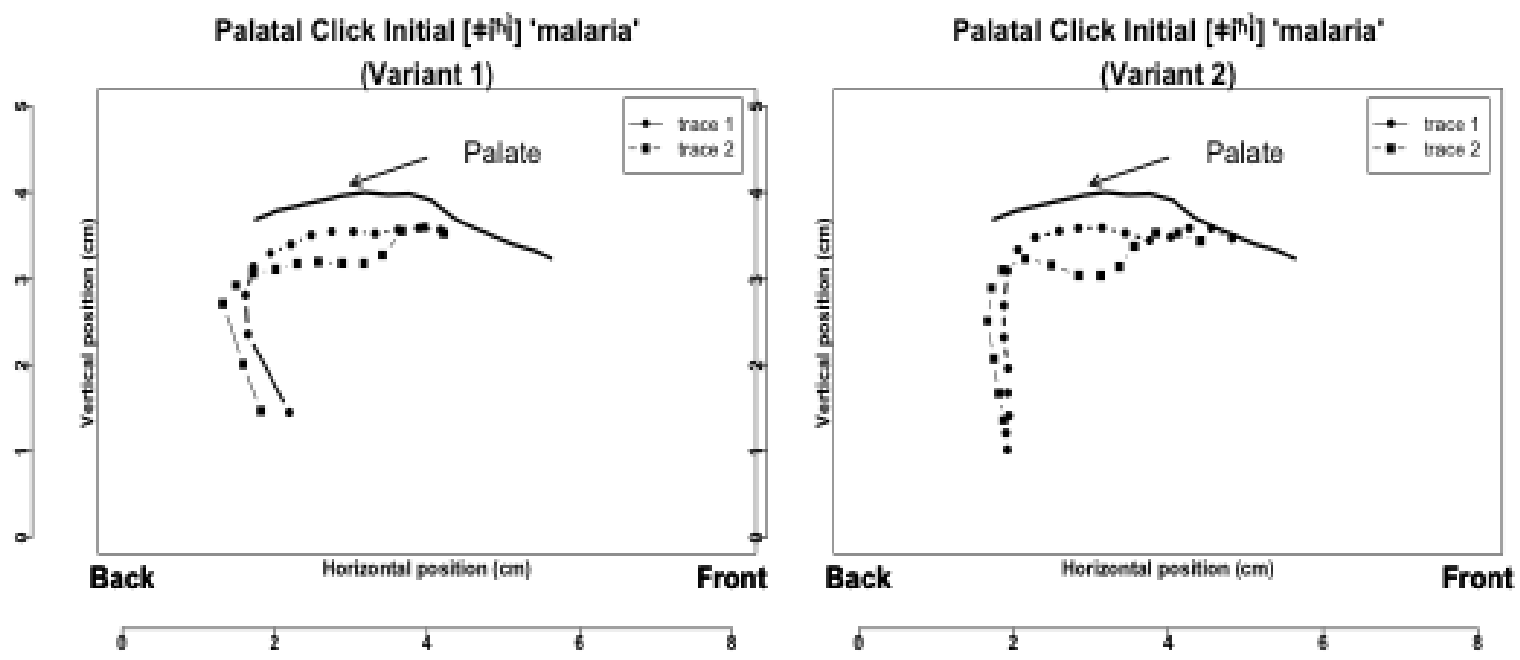

Figure 8 Two variants of the palatal click type produced by Speaker TK that display different types of rarefaction gestures from begin of closure to just before release of the anterior constriction

\subsubsection{Comparisons with the retracted dorsal stop}

The tongue traces at the beginning and end of the closure for the retracted dorsal consonant $[\underline{k}]$ in $[\underline{k} a]$ 'it' in the frame sentence are provided in Figure 9. We can compare the tongue dorsum and root positions for each speaker to the dorsal constrictions seen in the four click types.

The dorsal constriction and tongue root positions in the dental, alveolar and lateral click types are quite similar to the positions seen for the retracted dorsal $[\underline{k}]$ in $[\underline{k a}]$ 'it' in the frame sentence, in terms of the tongue dorsum constriction location, shape and width. This is in spite of the fact that the dental click type in the word used in this study occurs following the mid front vowel [e] in the preceding word 'say' in the carrier phrase, and precedes the high front vowel [i] in the target word. The data thus shows that there is a lack of coarticulation between the tongue dorsum constriction and the following high front vowel. This makes the tongue dorsum constriction in the dental click type different from the tongue dorsum constriction in the velar plosive, which coarticulates heavily with a following vowel in this language (Krebs, Sedarous and Miller, 2013). The tongue dorsum and root positions seen in the palatal click type in Figure 8a-c differ from the tongue root positions seen for the retracted dorsal stop in Figure 9. The dorsal constriction in the palatal click type is higher and farther back than the dorsal constriction seen in the retracted dorsal stop, and the tongue root is raised and bunched in the upper oro-pharynx in the palatal click type, and is not retracted into the mid to lower pharyngeal region as it is in the retracted dorsal stop. 

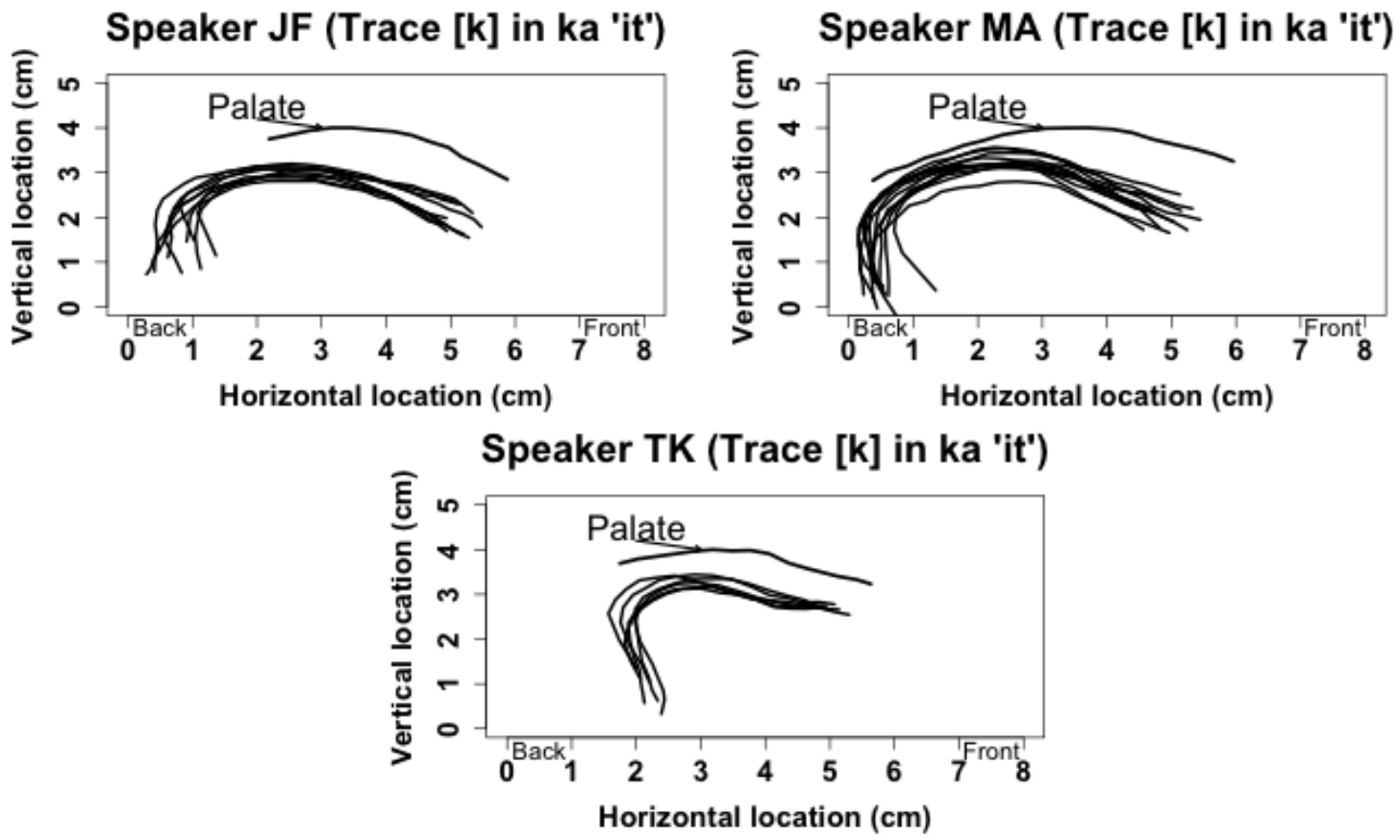

Figure 9 Lingual traces from the final frame in the [k] closure in the word $k a[k a]$ 'it' in the frame sentence

\subsection{Static Tongue Dorsum Constriction Location and Height Differences Just Prior to the Anterior Release of the Click}

Figure 10 provides boxplots of the Tongue Dorsum constriction locations (horizontal locations of the constrictions) at T2 for the four different syllable types for the three speakers' productions. The mean and standard deviation range values for the Tongue Dorsum constriction locations at T1 and T2 are provided in Table A. The Tongue Dorsum constriction locations for the 'ka' syllable type are forward of the Tongue Dorsum constriction locations for the [!อi] and [\|əi] syllable types for Speakers JF and TK, while the dorsal constriction in the ' $\mathrm{ka}$ ' syllable type is behind the Tongue Dorsum constriction locations for the [!əi] and [\|əi] syllable types for Speaker MA. 

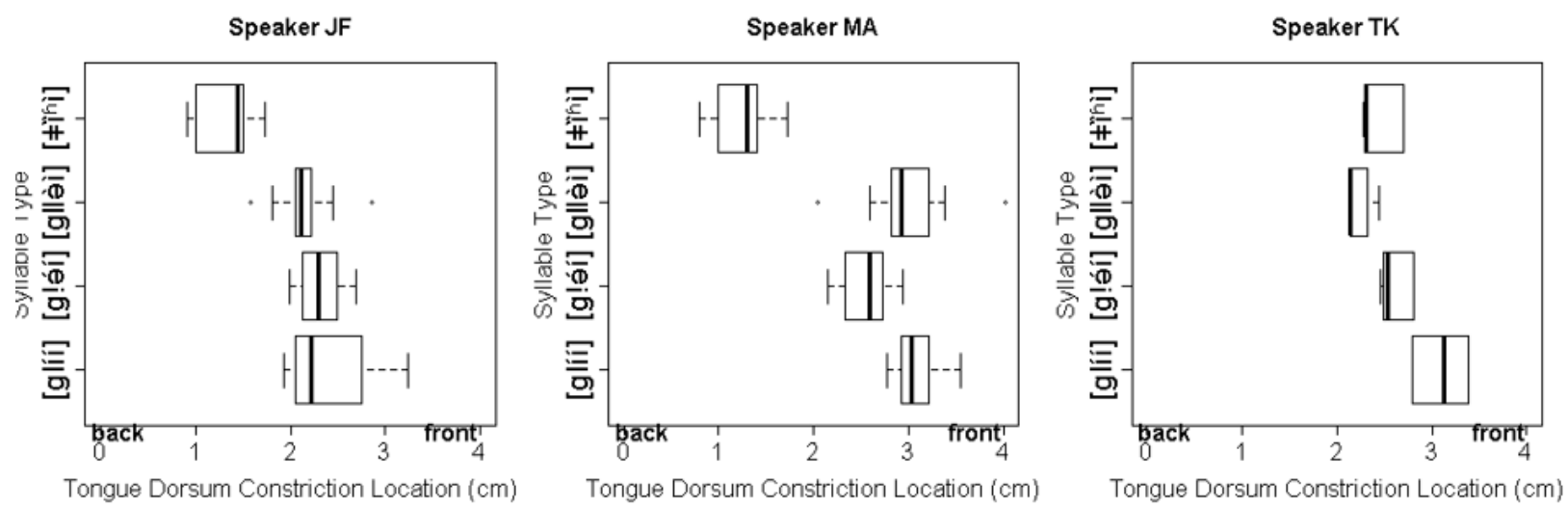

\section{Figure 10 Tongue Dorsum Constriction Locations associated with the four click-initial syllable types for speakers JF, MA and TK}

Table B in the appendix provides the results of regressions looking at the relationship between the Tongue Dorsum Constriction Location at T2 with the syllable type, comparing the palatal click initial syllable type to the other three pre-palatal click initial syllable types. For Speakers JF and MA, the Tongue Dorsum Constriction location for all of the pre-palatal click types are significantly in front of the Tongue Dorsum Constriction Locations for the palatal click type. There is variability in the amount of difference that is found for each click type that is compared, and for each speaker. For JF, the differences between all of the pre-palatal click initial syllable types and the palatal click initial syllable types are close to $1 \mathrm{~cm}$. For Speaker MA, the differences are all greater than $1 \mathrm{~cm}$. The differences found between speakers seem to indicate differences in the Tongue Dorsum constriction locations found in the lateral click types produced by the two speakers. The Tongue Dorsum constriction location on the mid-sagittal plane for the lateral click type is close to the Tongue Dorsum constriction location found for the dental click type for Speaker MA, while it is even further back than the alveolar click type for Speaker JF. For Speaker TK, the only significant difference in the Tongue Dorsum constriction location occurs between the dental and palatal click types, and the difference, at first, appears to be relatively small compared to the other speakers. It should be kept in mind that TK is a female speaker, and her overall mouth size is relatively small compared with the other two speakers, who are both male. The difference in TK's productions is thus probably relatively comparable in size to the greater differences found for the two male speakers.

Table $\mathrm{C}$ provides regressions comparing the 'ka' syllable type to the four click initial syllable types. For speakers JF and MA, the tongue dorsum constriction location in the palatal and lateral click types are significantly behind the TD constriction location in ' $k a$ ', while for Speaker TK, the TD constriction location in the four click types is significantly behind that found in ' $k a$ '.

Figure 11 provides boxplots of the Tongue Dorsum constriction height measurement for each of the four click-initial syllable types. Table D provides the results of the regressions of Tongue Dorsum Height at T2 against syllable type for the three speakers. These results show that for the two male speakers (JF and MA), the Tongue Dorsum Height is only slightly lower, but significantly lower, in the palatal click type compared with the other three click types for speaker JF. However, for speaker MA, the Tongue Dorsum is lower by at least $0.5 \mathrm{~cm}$ relative to the other click types. These results must be interpreted differently for the different speakers. For MA, the lower tongue dorsum height means that the soft palate must also be lower in his productions. From looking at the plot of the palatal click type for MA in Figure 8b, it is clear that his tongue dorsum is as far back in the palatal click type as in the ' $\mathrm{k}$ ' in $k a$. 

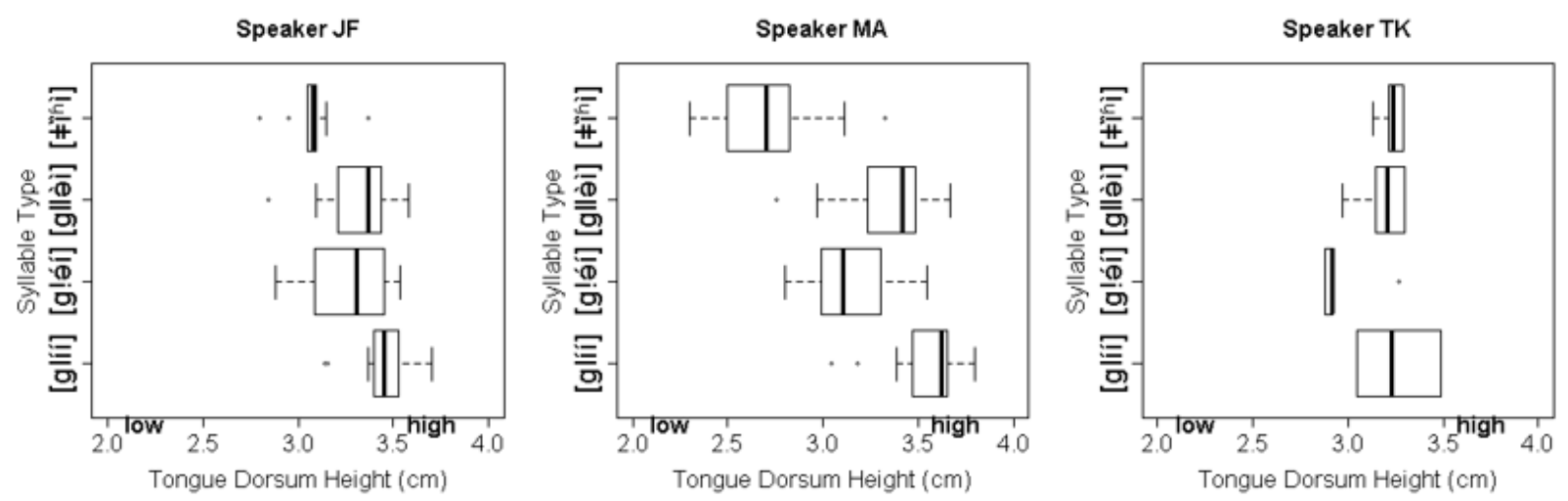

Figure 11 Tongue Dorsum Constriction Height associated with the four click-initial syllable types for Speakers $J F, M A$ and $T K$

\subsection{Static Tongue Root Position and Height differences just prior to the Anterior Release of the Click}

Figure 12 provides boxplots showing the horizontal location of the farthest back Tongue Root positions for the four click types for the three speakers. Table E provides the results of regressions that investigated the relationship between the Tongue Root constriction location and the anterior constriction location, comparing the palatal click initial syllable type to the other three pre-palatal click initial syllable types. For two out of the three speakers in the current study, the farthest back position of the tongue root occurs at different vertical locations in the palatal click initial syllable type compared with the three pre-palatal click initial syllable types. Table F provides the regressions comparing the Tongue Root Constriction Location at $\mathrm{T} 2$ in ' $\mathrm{k}$ ' in ka with those in the four click-initial syllable types.
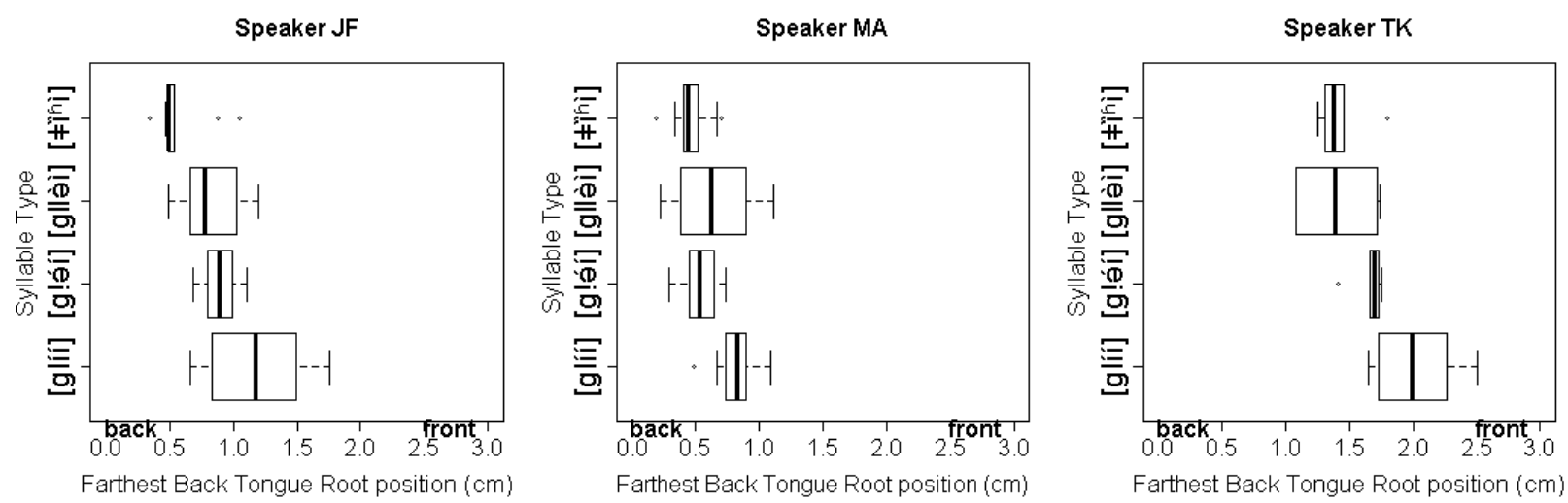

Figure 12 Boxplots showing the horizontal location of the farthest back tongue root position for the different click types for speakers JF, MA and TK

Figure 13 provides boxplots showing the height of the farthest back tongue root position for the different click types, and Table G provides the results of the regression showing the effect of syllable type on the height of the farthest back position of the tongue root. The height of the Tongue Root only differs significantly between the palatal and alveolar click types. The Tongue Root constriction location in the palatal click type is $0.45 \mathrm{~cm}$ above the Tongue Root constriction location found in the alveolar click type. The difference seen between the Tongue Root position in the dental and palatal click types is almost negligible, showing that the tongue root retracts high in the upper pharynx in both of these click types. The lateral click type is more variable, leading to no significant difference between the palatal and lateral click types. This variability is likely due to the fact that the measurements provided here are taken on the 
mid-sagittal plane. We can hypothesize that the greatest tongue root retraction may occur on the lateral plane in this click type.
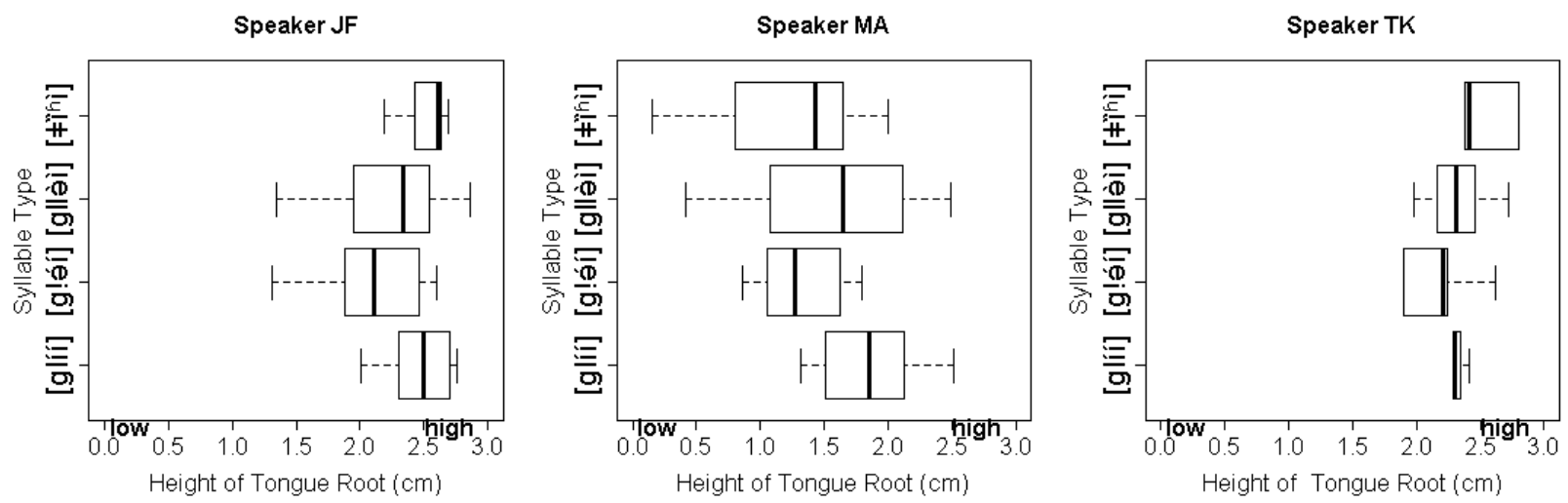

Figure 13 Boxplots showing the effect of syllable type on the height of the farthest back position of the tongue root

Speaker TK's productions display a similar effect. Her productions do not show much difference in the height of the farthest back Tongue Root position between the dental and palatal click types, which again suggests that the Tongue Root is bunched in the majority of her productions of both of these click types. Similar to JF, her productions display a clear difference between the height of the farthest back Tongue Root position in the palatal and alveolar click types. As with JF's productions, TK's productions display a much lower constriction found in the mid oro-pharynx in the alveolar click type, and a much higher Tongue Root position in the palatal click type. The difference is about $.70 \mathrm{~cm}$.

Speaker MA's productions display a different pattern. His productions of the dental click type display a Tongue Root position that is about $0.63 \mathrm{~cm}$ higher than is found in his productions of the palatal click type. His productions also show a different pattern between the alveolar and palatal click types, which both seem to have the Tongue Root positions at a similar place in the mid oro-pharynx. Like the other speakers, there is a great degree of variability in the Tongue Root height of the lateral click type, which is likely related to the fact that these measurements are on the mid-sagittal plane (not in the lateral margins). Based on these measurements, it can be concluded that the farthest back tongue root position in the production of the alveolar click type is in the mid oro-pharynx, while the farthest back Tongue Root position in the palatal click type is in the upper pharynx, given that the soft palate is higher in the palatal click type for Speaker JF. This suggests that the tongue root is bunched in JF's productions of the palatal click type, as it is in the bunched variant of American English ' $r$ ' that occurs in front vowel contexts (Ong and Stone 1998; Stavness et al. 2012; Archangeli et al. 2011, Mielke et al. To Appear). MA's productions show the opposite pattern. The farthest back tongue root position in his productions of the palatal click type is lower, due to the overall downward slope of the tongue from back to the front in his productions. Thus, speaker MA seems to have a third constriction made by the tongue root proper in his productions of the palatal click type, that are more similar to his productions of the alveolar click type.

\subsection{Rarefaction Gestures}

Table A provide the mean amount of movement (T1-T2 values) during the closure phase of the four syllable types for the three speakers, along with the Tongue Dorsum and Tongue Root constriction location measurements taken at T1 and T2. Higher numbers in the constriction location measurements indicate positions that are more forward, and lower numbers indicate more retracted positions. Positive 
differences indicate retraction, and negative differences indicate advancement.

Figure 14 provides boxplots showing the change in Tongue Dorsum constriction location from T1-T2 during the closure of the clicks in all four of the click initial syllable types, and during the closure of ' $\mathrm{k}$ ' in the $k a$ syllable type. Speaker MA's productions display a large difference in the Tongue Dorsum constriction location from the beginning to the end of the closure phase between the palatal click type and the other three click types. The dental, alveolar and lateral click types pattern with ' $\mathrm{k}$ ' in displaying little to no tongue dorsum retraction during the closure. The boxplot for Speaker JF shows that the ' $\mathrm{k}$ ' in $k a$ displays extreme tongue dorsum advancement in his productions. This is because his productions display extreme vowel reduction in the pronoun $k a$, leaving the ' $\mathrm{k}$ ' adjacent to the palato-alveolar affricate in the word $\widetilde{d z}$ ala 'good'. His productions do display a difference between the palatal and the pre-palatal click initial syllable types, that is similar to the difference found for Speaker MA's productions, although it is not quite as large. Speaker TK's production are similar to MA's productions, in that the palatal click type displays retraction not found in the other three pre-palatal click types, which are all similar to ' $\mathrm{k}$ '. Table $\mathrm{H}$ provides the results of the regressions of change in the Tongue Dorsum Constriction location during the closure (T1-T2) against the anterior constriction location, comparing the palatal click type to the three pre-palatal click types. The differences between the palatal and the three pre-palatal click initial syllable types are significant. The Tongue Dorsum movement seen in the palatal click type is likely in response to movement in the anterior constriction that has been shown to occur in !Xóõ by Ladefoged and Traill (1994, see their Figure 2), but differences in tongue front movement have not been investigated for Mangetti Dune!Xung clicks.
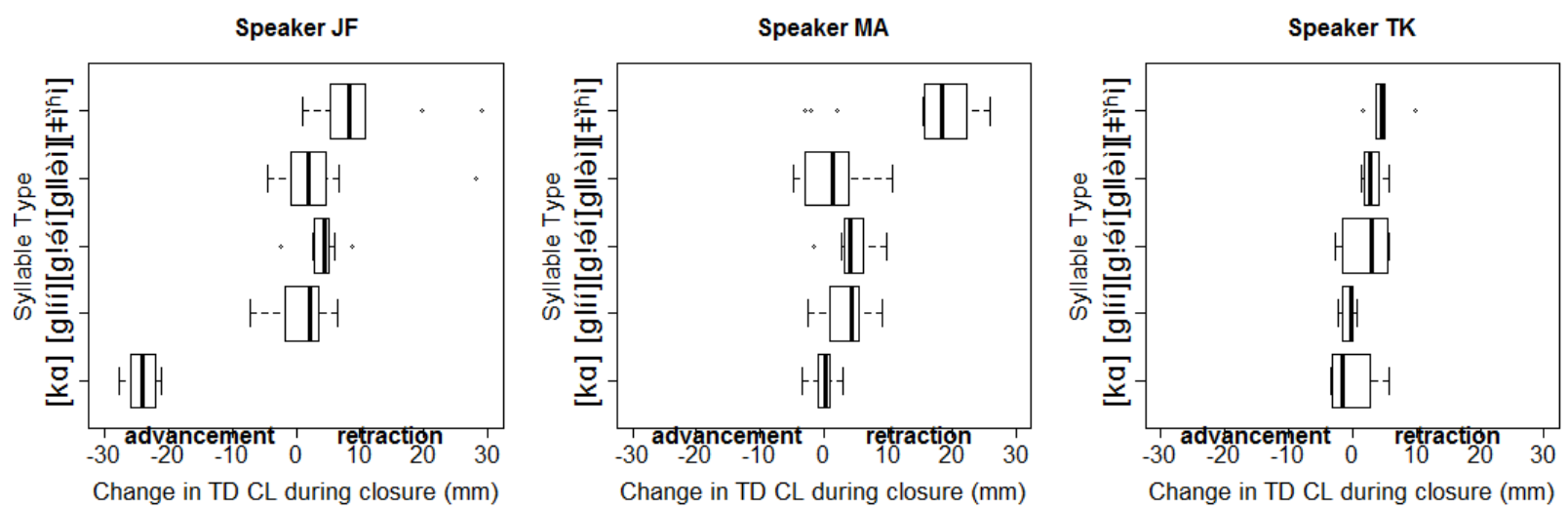

Figure 14 Differences between tongue dorsum constriction locations at T1-T2 for all four click types produced by all three speakers

Table I provides results of regressions that were run to determine if the amount of tongue dorsum retraction in [k] in $k a$ differs significantly from the amount of tongue dorsum retraction in the four click types. JF's results display much greater tongue dorsum retraction in the four click types than with ' $k$ '. For Speaker MA, there are no significant differences between the dental, alveolar and lateral click initial syllable types and the [k] initial syllable type, showing that the retraced velar and the three pre-palatal click initial syllable types exhibit similarly small degrees of tongue dorsum retraction during the closure. MA's productions exhibit a significantly greater degree of tongue dorsum retraction during the closure of the palatal click type than in [k] in 'ka'. Speaker TK produces a significantly greater degree of tongue dorsum retraction in $[\mathrm{k}]$, than in the four click types. Referring to Figure 14, we can see that there is little to no tongue dorsum retraction in the three pre-palatal click types, and only slight tongue dorsum retraction in the palatal click type. Thus, the greater retraction in $[\mathrm{k}]$ in ' $\mathrm{ka}$ ' is not surprising. 
Figure 15 provides boxplots showing the change in Tongue Root position from T1-T2 against syllable type. Speaker JF's and TK's productions display retraction of the Tongue Root from the beginning of the closure phase (T1) to the end of the closure phase (T2). However, the amount of retraction is rather small for JF, but rather large $(0.5 \mathrm{~cm})$ for TK. This amount of retraction is quite large for speaker TK, given that as a female speaker, she has a smaller vocal tract overall.
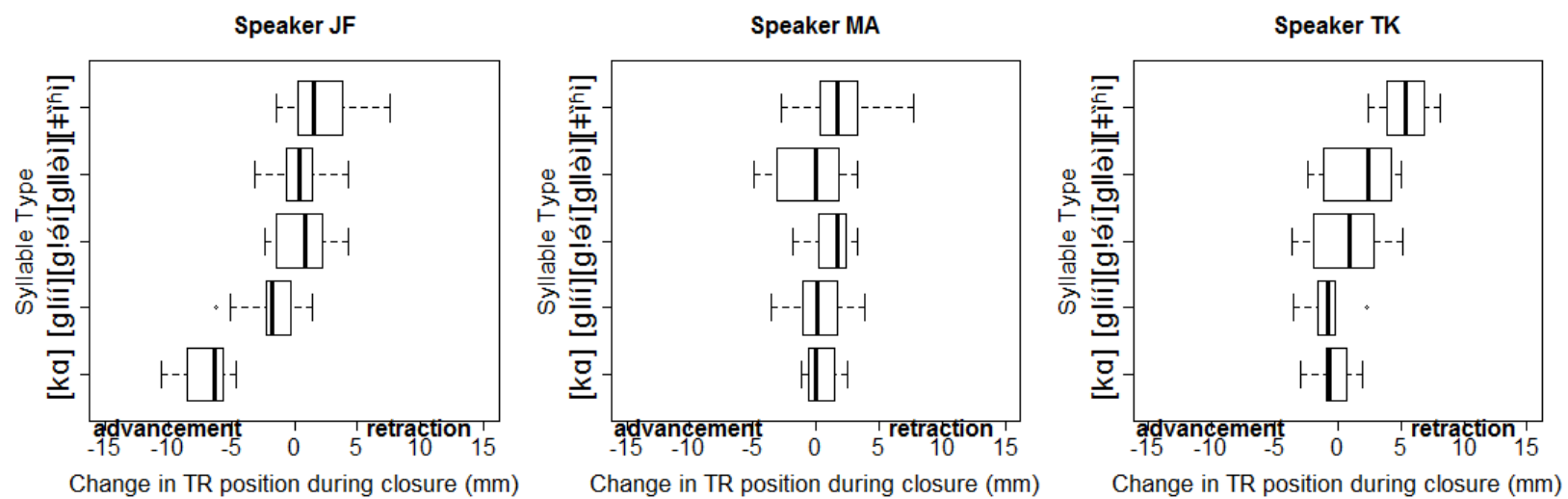

Figure 15 Differences in horizontal tongue root position during closure phase (T1-T2) of the four contrastive click types

Table $\mathrm{J}$ provides the results of the regression for each speaker showing the differences between the Tongue Root positions at the beginning of the closure phase (T1) and at the end of the closure phase (T2). Comparing these differences to the mean static Tongue Root constriction locations at T1 and T2 in Table $\mathrm{J}$, it is apparent that the negative differences in Tongue Root movement between the palatal click type and the three pre-palatal click types, are due to the fact that the palatal click type displays the largest retraction in the Tongue Root constriction location during the closure phase. The dental click type exhibits forward movement of the Tongue Root, leading to a small mean negative difference value. The alveolar and lateral click types exhibit very little movement in the Tongue Root position in either direction. Table $\mathrm{K}$ contains the regressions comparing the amount of tongue root retraction in ' $\mathrm{k}$ ' in $k a$ to the four click initial syllable types.

It is extremely important to note that the Tongue Root movements are occurring in different areas of the pharynx for the different click types for two out of three speakers (JF and TK), as has been shown in Figure 13 in Section 4.3. In the palatal click type, the retraction occurs in the upper oro-pharynx for speaker JF due to raising and bunching of the tongue root, but the retraction occurs in the lower pharynx for speaker MA and for the variants of TK's productions that contain TR retraction (e.g. Variant 1 type). The retraction found in the other three pre-palatal click types occurs in the mid to lower pharynx, which is more typical of tongue root retraction that induces vowel retraction and lowering in well-known cases of pharyngeal assimilation such as Arabic (Herzallah 1990) and Salishan (Bessel 1997), and in the [əi] variants of /i:/ that follow the alveolar and lateral click types in the Kx'a languages.

\subsection{Discussion}

The first research question (Q1) addresses overall tongue shape. The first hypothesis (H1) was that the tongue shape of the dental and palatal click types would be relatively flat, with broad anterior and posterior constrictions, while the tongue shape of the alveolar and lateral click types would be more concave with narrow anterior constrictions and deep tongue body wells. The tongue plots shown in 
Figures 8a-c showed that the dental click type does indeed have a more flat tongue body shape with a shallow tongue body well, and more flat anterior and posterior constrictions, for 2 of the 3 speakers (JF and TK) studied. The third speaker (MA) provides a bit of a deeper lingual cavity well, which is shorter, leading to a similarly small lingual cavity. Thus, it appears that the dental click productions by the three speakers studied here seem to always have a relatively small lingual cavity, whether that be due to shortness of the cavity or shallowness of the cavity. H1 is thus not supported by the dental click data.

The palatal click type shows a great deal of within speaker and across speaker variation in tongue shape and in the depth of the lingual cavity. One of the speakers' (MA) productions of the palatal click type supports H1, as the tongue shape is relatively flat. However, the posterior constriction for two out of the three speakers' (JF and TK) productions is surprisingly narrow and peaked, and the tongue body well is relatively deep. Thus, the tongue shape in the palatal click type does not provide consistent support for $\mathrm{H} 1$, the "flat vs. concave tongue shape" hypothesis.

The alveolar click type supports H1. This click type exhibits the largest tongue body well, and an extremely concave tongue shape, with a peaky anterior constriction. The lateral click type exhibits a mid tongue body depth, somewhere in between the shallow well in the dental click type, and the deep well in the alveolar click type. The front and back constrictions are not as peaky as those seen in the alveolar click type.

We can conclude that $\mathrm{H} 1$ is well supported for the dental and the alveolar click types, but the hypothesis is only well supported for one variant of the palatal click type. The hypothesis is also not well supported by the lateral click type, but this may well be due to the limitation of the current study to mid-sagittal ultrasound data. Sagittal data in the lateral margins, or 3D ultrasound data, would help resolve these issues. Thus, the unexpected results with respect to tongue shape seen here are due to unexpected variation seen in the production of palatal click initial syllables that display variation both within speaker and within the same lexical item. Miller (In progress) shows that these syllables also display variation in the realization of the vowels, which are not all monophthongal high front vowels as described for other languages (e.g. Traill 1985; Miller-Ockhuizen 2001).

The second research question $(\mathrm{Q} 2)$ addresses tongue dorsum and tongue root positions found in the four coronal click types, and their comparison to the tongue dorsum and root constrictions in [k] in $k a$. The results support Hypothesis $2 b$, in showing that the tongue dorsum position is farther back in the palatal click type than in the three pre-palatal click types and [k]. This seems to reflect a physiological necessity. The posterior constrictions in the palatal click type must necessarily be further back in order to accommodate the further back anterior constriction, while still allowing formation of a lingual cavity that is the airstream source - a critical component of click production.

The current study has shown that the tongue dorsum constriction locations in the dental, alveolar, and lateral click types are quite similar to those in the retracted velar plosive. This is in keeping with hypothesis 2a, the "Vowel Context Hypothesis" for the alveolar and lateral click types, but not for the dental click type. It is surprising that the dental click type, which is studied here in the [i:] context, does not have a fronted dorsal constriction. Thus, it seems that the tongue dorsum constrictions in the four click types are back velar or uvular, and not the fronted velar constriction seen in $/ \mathrm{k} /$ is in the [i] context in the language (Krebs, Sedarous and Miller 2013). Since it is unknown how the posterior constrictions in click types differ in different vowel contexts in Mangetti Dune !Xung, we cannot ascertain whether the posterior constrictions in clicks coarticulate less with following vowels than other consonants. Both patterns appear to exist in different languages. Sands (1991) showed that there was little C-V 
coarticulation involved in Xhosa clicks based on acoustic click burst spectra. However, the posterior constriction locations in clicks have been shown to be more forward in front vowel contexts in the Zulu dental and palato-alveolar click types (Thomas-Vilakati 2010).

The height of the Tongue Dorsum constriction in the palatal click type differs in various ways for the different speakers from the height of the Tongue Dorsum constriction in the pre-palatal click types. Height differences go hand in hand with constriction location differences, as the different constriction locations follow the curvature of the vocal tract, and farther back constrictions are necessarily also lower in height.

The second subquestion of Question 2 (Q2) addresses tongue root position in the clicks and [k]. The tongue root positions differ among click types, and there is a good deal of inter-speaker variation in the tongue root positions found in the palatal click type. One of the three speakers (JF) raises and bunches his Tongue Root in the production of the palatal click type in all of his productions, and another speaker (TK) raises and bunches the tongue root in only some of her productions, resulting in a raised tongue root in the upper part of the oro-pharynx in these productions. While the ultrasound traces are somewhat ambiguous as to whether the tongue root is raised, or whether it is just not visible in the ultrasound videos (and thus not traced), the videos provided in the supplemental material disambiguate this, as they show that the tongue root is raised and bunched in JF's productions.

The third research question (Q3) addresses whether the various click types might involve tongue dorsum or tongue root retraction. H3a, "The Tongue Root Retraction vs. Tongue Bunching" hypothesis, predicts that the alveolar and lateral click types would involve tongue dorsum and /or tongue root retraction in the mid to lower pharynx that is not found in the dental and palatal click types. The alternative hypothesis, $\mathrm{H} 3 \mathrm{~b}$, hypothesized that the palatal click type would involve tongue dorsum and / or tongue root retraction that is not found in the pre-palatal click types. At first blush, the results support H3b, as the palatal click type displays more tongue dorsum and root retraction than is found in the three pre-palatal click types. However, it is extremely important to notice that the part of the pharynx where the tongue root is retracting is quite different in the palatal click type compared to the three pre-palatal click types. For Speaker JF's and some of speaker TK's productions, the tongue root is raised and bunched into the upper part of the pharynx in the palatal click type, while the tongue root proper is retracting into the lower pharynx in the production of [k] and the dental, alveolar and lateral click types. Traill (1985) provides xray traces of several frames during the production of the five !Xóõ clicks superimposed on traces of the front vowels. The data show that the tongue is minimally distorted from the tongue shapes for [i] in the dental and palatal click productions, but shows major distortion away from the [i] position in the alveolar and lateral click types. He claims that the difference are best captured in terms of the laminal vs. apical anterior constrictions of the clicks, but the X-ray traces provided in his study, and the ultrasound traces provided in the current study, show that large difference in position of the tongue root and the kinematics of the back part of the tongue in click production also exist. In at least some speakers productions of the palatal click type, the tongue root bunches and raises. In the dental click type, the tongue root advances. In the alveolar and lateral click types, the two clicks that retract and lower a following /i:/ vowel, the tongue root retracts into the mid to lower pharynx. Therefore, the main departure from hypothesis $\mathrm{H} 3 \mathrm{~A}$ is that the dynamics of the dental and palatal click types are not parallel. These two clicks have different kinematics that result in their compatibility with the high front vowel [i]. Of course, we must recognize that some speakers (MA) produce palatal clicks involving tongue root retraction, which raises the question of how they are compatible with [i]. 
It can be surmised that the palatal click type is compatible with [i:] in productions where the kinematics of the tongue root involves bunching and raising of the tongue root into the upper pharyngeal region. This differs from the tongue tongue root retraction into the mid to lower pharynx that is typically found in uvular consonants, and is found in the alveolar click that is incompatible with [i:] in the current study. The dental click type exhibits a small, but not significant, degree of tongue root advancement. This may provide an explanation for its compatibility with [i:]. That is, even though this click type has a similar tongue dorsum constriction location to [k] in ' $\mathrm{ka}$ ' and the alveolar and lateral click types, it does not exhibit tongue root retraction in the mid to lower pharynx that occurs in the alveolar and lateral click types. Thus, a modified version of Hypothesis $2 \mathrm{~b}$ is supported, once both passive and active articulators are taken into account.

The increased articulatory distance between the active and passive articulators involved in the uvulopharyngeal constriction of the palatal click type may provide at least a partial explanation for its crosslinguistic rarity. If a language only has three click types, it always lacks the palatal click type (Miller 2011). Additionally, the palatal click type seems to have the lowest lexical frequency of the coronal click types in languages where this has been investigated. For example, Brugman (2009) provides percentages of roots that begin with different clicks in Khoekhoe from Haacke and Eiseb's (2002) dictionary. The alveolar click type is the most frequent, occurring in initial position of $21 \%$ of roots. The dental click is the next most frequent occurring in $19 \%$ of roots. The lateral click initiates $17 \%$ of roots, and the palatal click type is the least frequent, initiating only $15 \%$ of roots. This differs slightly from Traill's (1985: 162) numbers, which include clicks with all closure and release properties (e.g. accompaniments). He notes that in !Xóõ, dental click types initiate $12.7 \%$ of roots, the palatal click type initiates $15.1 \%$ of roots, and the alveolar and lateral click types initiate $18.9 \%$ and $18.6 \%$ of roots respectively. The different frequencies for the dental and palatal click types in Khoekhoe and !Xóõ may illustrate language differences, but they may also be due to differences in frequencies of voiceless unaspirated clicks that Brugman counted vs. clicks combined with different closure and release properties that Traill counted. This hypothesis is in keeping with Lindblom and Maddieson's (1988) claim that displaced articulations are more costly in terms of articulatory effort than more direct movements.

The results of the current study are now compared to the Electropalatographic results of Zulu clicks provided by Thomas-Vilakati (2010). She measured a posteriority index, which counts the number of contacted electrodes on the posterior part of the pseudo palate for the Zulu consonants. The results, provided in her Figure 3.43, show that the Zulu velar stop and the dental click type have a similar number of contacted electrodes, which she interprets as showing that both of these consonants have forward posterior constrictions. The palatal-alveolar click type has fewer contacted electrodes in the posterior region, followed by the lateral click type, which has even fewer contacted electrodes on the back of the palate, providing evidence that the posterior constrictions of the palatal-alveolar and lateral click types are post-velar, as opposed to the dental click type and the velar stop which have more fronted velar articulations. It is important to note that Zulu contains 3 contrastive click types, and does not contain a contrast between palatal and alveolar click types.

Differences in the types of measures being reported explain some of the differences between the results of the current study and Thomas-Vilakati's study. The EPG measures are capturing the front edge of the dorsal contact with the palate, while the ultrasound measurements presented here looked at the peak of the tongue dorsum, which is expected to correlate with the middle of the lingual contact on the velum. However, there still seem to be language specific differences in the articulation of Zulu and Mangetti Dune !Xung consonants. Namely, the $[\mathrm{k}]$ and the dental and alveolar click types have similar tongue dorsum constriction locations for two of the three speakers of Mangetti Dune !Xung, while the [k] and [!] 
clicks differ in posterior constrictions in Zulu. The tongue dorsum constriction location in the lateral click type is behind that seen in ' $\mathrm{k}$ ' in both languages.

Research is in progress to investigate the acoustic and articulatory realizations of the high front vowel phone following the four coronal click types in Mangetti Dune !Xung. Investigations will determine if the two articulatory variants of the palatal click type co-occur with different vowel realizations (Miller, 2013; Miller, In Progress) and different acoustic realizations of the click bursts seen in Miller and Shah (2009). Preliminary results suggest that there are four distinct allophones of /i:/ following the four clicks: [ii], [ii], [əi] and [e:], rather than the two described in !Xóõ (Traill 1985) and Ju|'hoansi (Miller-Ockhuizen 2000). Descriptions of the acoustic and articulatory variants of words containing the palatal click type followed by /i:/ that occur in Mangetti Dune !Xung may shed light on the phonetic mechanism involved in the diachronic innovative sound change from the proto-palatal click type to a click type in the related Kx'a language Ekoka !Xung (Sands 2010) that is not currently recognized by the IPA (2006). König and Heine (2010) describe this unrecognized click as a retroflex click, but they note that they are unaware of its phonetic realization. Miller and Holliday (2014) provide articulatory and acoustic data that lead to their description of this click as a fricated laminal post-alveolar click, which may be more similar to the apical variant of the palatal click produced by Speaker TK. Further research on the articulatory and acoustic realizations of the unrecognized Ekoka !Xung click are in progress.

\subsection{Conclusion}

Tongue Dorsum and Tongue Root measurements of high frame rate (114 fps) lingual ultrasound data of the four coronal click types, and the retracted variant of $/ \mathrm{k} /$, reveal that the dental, alveolar and lateral click types exhibit dorsal constrictions that are similar to the retracted variant of $[\mathrm{k}]$ that occurs preceding the back vowel [a]. The dorsal constriction of the palatal click type is significantly behind the dorsal constrictions found in $/ \mathrm{k} /$, and the other three click types. This is surprising given that the dental and palatal click types co-occur freely with [i:], while the alveolar and lateral click types retract and lower /i/ to [əi]. There is a third lingual constriction involving the tongue root proper into the lower pharynx in the alveolar and lateral click types, while the pharyngeal constriction seen in the palatal click types is high in the oro-pharynx, and is best interpreted as the back edge of a single uvulo-pharyngeal constriction in most speakers' productions. However, there is a great deal of within and across speaker variation in the production of the palatal click type, and it is expected that this variation in palatal click production will predict the variation in the realization of the /i/ vowels that follow this click type. The main difference between the dental and palatal click types that co-occur freely with [i], and the alveolar and lateral click types that both retract and lower the /i/ vowel to [əi] lies in the kinematics. The clicks that retract and lower /i/ both exhibit retraction of the tongue root proper into the mid to lower pharyngeal region. The dental click type, on the other hand, exhibits tongue root advancement (not retraction). Over half of the palatal click productions in the current study involve bunching and raising of the tongue root into the upper pharyngeal region. But there is a second variant of this click type that is similar to the alveolar click type in its production. The variation seen in the production of the palatal click type in a Kx'a language is expected to shed light on both synchronic and diachronic sound changes involving the palatal click type in the Kx'a language family.

\section{Acknowledgments}

I acknowledge the support of Chief John Arnold and Councilor Costa Swau as well as logistical assistance from Sara Sungu and Tina Kalezi. I thank Rev. Van Zyl and the Mangetti Dune Dutch Reformed Church Council, who allowed us to use their church for recording purposes. I acknowledge the 
assistance of Bonny Sands and Sheena Shah with data collection, and Abigail Scott, Ping Bai, Vicki Lynn Krebs and Yourdanis Sedarous for assistance with data processing, as well as Ping Bai for assistance with R scripting. I acknowledge the support of two National Science Foundation grants: Explaining the Rarity of Clicks as Consonants in the Languages of the World (\#BCS-1123634, PI A. Miller) and Collaborative Research: Phonetic and Phonological Structures of Post-velar Constrictions in Clicks and Laterals (\#BCS-0726198, PIs A. Miller \& B. Sands) and a grant from the Endangered Languages Documentation Programme, A Video and Text Documentation of Mangetti Dune!Xung (\#SG012, PI A. Miller). 


\section{Reference List}

Abercrombie, D. (1967). Elements of general phonetics. Edinburgh: Edinburgh University Press.

Archangeli, D., Baker, A. and Mielke, J. (2011). Categorization and features: Evidence from American English $/ \mathrm{I} / *$. Where do phonological features come from?: cognitive, physical and developmental bases of distinctive speech categories. pp. 175-195.

Articulate Instruments Ltd. (2008). Ultrasound stabilization headset user's manual, Revision 1.3. Edinburgh: Articulate Instruments Ltd.

Aromo, M., Augumes, C., Fransisko, R., Kaleyi, T., Miller, A., Namaseb, L., Prata, D., Riem, S., Sands, S. and Shah, S. (2008). Mangetti Dune !Xung Dictionary. Unpublished Manuscript. The Ohio State University, The University of Namibia and Northern Arizona University.

Beach, D. M. (1938). The phonetics of the Hottentot language. Cambridge: W. Heffer \& Sons, Ltd.

Bessel, N. (1997). Phonetic aspects of retraction in Interior Salish. In Czaykowska-Higgins, E. \& Kinkade, MD (eds.) Salish Linguistics. The Hague: Mouton.

Brugman, J. (2009). Segments, Tones and Distribution in Khoekhoe Prosody. Ph.D. Dissertation, Cornell University.

Doke, C. M. (1923). Notes on a problem in the mechanism of the Zulu clicks. Bantu studies and general South African anthropology. 2,1, pp. 43-45.

Epstein, M. and Stone, M. (2005). The tongue stops here: Ultrasound imaging of the palate. Journal of the Acoustical Society of America, 118,4, pp. 2128-2131. doi: 10.1121/1.2031977.

Haacke, W. H. G. and Eiseb, E. (2002). A Khoekhoegowab Dictionary with an English-Khoekhoegowab Index. Windhoek: Gamsberg Macmillan.

Hastie, T. J. and Pregibon, D. (1992) Generalized linear models. Chapter 6 of Statistical Models in S. In J. M. Chambers and T. J. Hastie (Eds.), Wadsworth \& Brooks/Cole.

Heine, B. and Honken, H. (2010). The Kx'a family: A new Khoisan genealogy. Journal of Asian and African Studies. No. 79.

Heine, B. and König, C. (2012). The !Xun language: A dialect grammar of northern Khoisan. (Quellen zur Khoisan Forschung). Cologne: Rüdiger Kopper Verlag.

Herzallah, R. (1990). Aspects of Palestinian Arabic phonology: A Non-linear approach. Ithaca, NY: Cornell University Dissertation.

IPA. (2006). The International Phonetic Alphabet (revised to 2005) [chart]. Journal of the International Phonetic Association, 36(1), 135.

Johnson, K. (1993). Acoustic and auditory analyses of Xhosa clicks and pulmonics. UCLA working papers in phonetics, 83, pp 33-45. 
Krebs, V., Sedarous, Y. and Miller, A. (2013). C-V Coarticulation in Velar Plosives. Journal of the Acoustical Society of America vol. 133, 5. pp.3610.

Ladefoged, P. (2003). Phonetic data analysis: An introduction to fieldwork and instrumental techniques. Malden, MA: Blackwell.

Ladefoged, P. \& Maddieson, I. (1996). Sounds of the world's languages. Cambridge, MA: Blackwell.

Ladefoged, P. \& Traill, A. (1994). Clicks and their accompaniments. Journal of Phonetics, 22, 33-64.

Lee, D. April 2, 2013, General Electric Ultrasound Applications Specialist. Personal Communication.

Lindblom, B. \& Maddieson, I. (1988). Phonetic Universals in Consonant Systems, In C. Li and L. M. Hyman, Eds., Language, Speech and Mind, London: Routledge, 62-78.

Mielke, J., Baker, A. \& Archangeli, D. (To Appear). Individual-level contact limits phonological complexity: evidence from bunched and retroflex /. $/$. To Appear in Language.

Mielke, J., Baker, A., Archangeli, D. \& Racy, S. (2005). Palatron: A technique for aligning ultrasound images of the tongue and palate. In Siddiqi, D. \& Tucker, B. V. (Eds.), Coyote Papers 14, pp. 97-108.

Miller, A. (2010). Tongue body and tongue root shape differences in N/uu clicks correlate with phonotactic patterns In Fuchs, S., Toda, M. \& Zygis, M. (Eds.), Turbulent Sounds: An Interdisciplinary Guide, Interface Explorations, Berlin: Mouton de Gruyter.

Miller, A. (2011). The Representation of Clicks. In van Oostendorp, M., Ewen, C., Hume, E. and Rice, K. (Eds.). The Blackwell Companion to Phonology Vol.1 .Blackwell Reference Online. 24 October 2012.

Miller, A. (2013). C-V Coarticulation in consonants with multiple lingual constrictions. The Journal of the Acoustical Society of America 133, 5, pp. 3612.

Miller, A. (In Progress). C-V Coarticulation in Mangettti Dune !Xung coronal click types. Ms. The Ohio State University.

Miller, A., Brugman, J., Sands, B., Namaseb, L., Exter, M., \& Collins, C. (2009). Differences in airstream and posterior place of articulation among N|uu lingual stops. Journal of the International Phonetic Association 39, 2, 129-161.

Miller, A. and Holliday, J. J. (May 8, 2014). Contrastive apical post-alveolar and laminal alveolar click types in Ekoka!Xung. Journal of the Acoustical Society of America 135, 4, pp. 2351-2352.

Miller, A. and Finch, K. (2011). Corrected high frame rate anchored ultrasound with software alignment. April 2011, Journal of Speech, Language and Hearing Research, pp. 471-486. 
Miller, A. (2013). C-V Coarticulation in consonants with multiple lingual constrictions. The Journal of the Acoustical Society of America vol. 133 issue 5 May 2013. p. 3612, DOI: 10.1121/1.4806735.

ISSN: 0001-4966.

Miller, A., Namaseb, L. \& Iskarous, K. (2007). Tongue body constriction differences in click types. In Cole, J. \& Hualde, J. (Eds.), Laboratory phonology 9, pp. 643-656. New York: Mouton de Gruyter.

Miller, A., Scott, A., Sands, B. \& Shah, S. (2009). Rarefaction gestures and co-articulation in Mangetti Dune !Xung clicks. In: Uther, M., Moore, R. \& Cox, S. (Eds.), Proceedings of the $10^{\text {th }}$ Annual Conference of the International Speech Communication Association (Interspeech 2009). pp. 22792282. Brighton, U.K: Causal Productions.

Miller, A. and Shah, S. (2009) The Acoustics of Mangetti Dune !Xung Clicks. In M. Uther, R. Moore \& S. Cox, (eds.), Proceedings of the $10^{\text {th }}$ Annual Conference of the International Speech Communication Association (Interspeech 2009). Causal Productions: Brighton, U.K., pp. 2283-2286.

Miller-Ockhuizen, A. (2003). The Phonetics and phonology of gutturals: A case study from Ju|'hoansi, In Horn, L. (Ed.), Outstanding Dissertations in Linguistics Series, New York: Routledge.

Nakagawa, H. (2006). Aspects of the phonetic and phonological structure of the G|ui language. Ph.D. thesis, University of the Witwatersrand. Johannesburg.

Ong, D. and Stone, M. (1998). Three Dimensional Vocal Tract Shapes in [r] and [1]: A Study of MRI, Ultrasound, Electropalatography, and Acoustics, Phonoscope, 1, 1-14.

R Development Core Team (2011). R: A Language and Environment for Statistical Computing. R Foundation for Statistical Computing. Vienna, Austria, ISBN 3-900051-07-0.

Sagey, E. (1990). The representation of features in non-linear phonology: The articulator node hierarchy (Outstanding dissertations in linguistics). New York: Garland.

Sands, B. (1991). Evidence for click features: acoustic characteristics of Xhosa clicks. UCLA working papers in linguistics, 80, 6-37.

Sands, B. (2010). Juu subgroups based on phonological patterns. In Brenzinger, M. \& König, C. (Eds.), Khoisan Languages and Linguistics. Proceedings of the $1^{\text {st }}$ International Symposium January 4-8, 2003. Riezlern / Kleinwalsertal. Köln: Rüdiger Köppe Verlag.

Stavness, I., Gick, B., Derrick, D. and Fels, S. (2012). Biomechanical modeling of English /r/ variants. JASA Express Letters, Journal of the Acoustical Society of America, 131, 5, EL355-360.

Stone, M. (2005). A Guide to analyzing tongue motion from ultrasound images. Clinical Linguistics and Phonetics 19, 6-7, 455-502.

Thomas-Vilakati, K. D. (1999). Coproduction and coarticulation in isiZulu clicks. Ph.D. dissertation, University of California at Los Angeles.

Thomas-Vilakati, K. D. (2010). Coproduction and coarticulation in IsiZulu clicks. University of California Publications in Linguistics. Volume 144. Berkeley and LosAngeles, CA. University of California Press. 
Traill, A. (1985). Phonetic and phonological studies of !Xóõ Bushman (Quellen zur Khoisan-Forschung 1). Hamburg: Helmut Buske Verlag. 


\section{Appendix A. Statistical Tables}

Table A. Mean tongue dorsum and tongue root constriction locations at T1, T2 and tongue dorsum and tongue root movement during closure (T1-T2)

\begin{tabular}{|c|c|c|c|c|c|c|}
\hline \multirow[t]{2}{*}{ Syllable Type } & \multicolumn{3}{|c|}{$\begin{array}{c}\text { TD Position at Begin Closure (T1), } \\
\text { End Closure (T2), and } \\
\text { TD Movement During Closure }\end{array}$} & \multicolumn{3}{|c|}{$\begin{array}{l}\text { TR Position at Begin Closure (T1) } \\
\text { and End Closure (T2), and } \\
\text { TR Movement During Closure } \\
(\mathrm{cm})\end{array}$} \\
\hline & $\begin{array}{l}\text { Beg. } \\
\text { Closure } \\
\text { (T1, } \\
\text { cm) }\end{array}$ & $\begin{array}{c}\text { End } \\
\text { Closure } \\
(\mathrm{T} 2, \mathrm{~cm})\end{array}$ & $\begin{array}{l}\text { Movement } \\
\text { during } \\
\text { closure } \\
(\mathrm{T} 1-\mathrm{T} 2, \mathrm{~cm})\end{array}$ & $\begin{array}{l}\text { Beg. } \\
\text { Closure } \\
\text { (T1, } \\
\text { cm) }\end{array}$ & $\begin{array}{c}\text { End } \\
\text { Closure } \\
(\mathrm{T} 2, \mathrm{~cm})\end{array}$ & $\begin{array}{l}\text { Movement } \\
\text { during } \\
\text { closure (T1- } \\
\text { T2, cm) }\end{array}$ \\
\hline \multicolumn{7}{|l|}{ Speaker JF } \\
\hline $\begin{array}{l}\text { Dental click } \\
\text { initial [ }{ }^{\mathrm{g}} \mid \mathbf{1} 1 \text { ] }\end{array}$ & $\begin{array}{c}2.48 \\
(0.41)\end{array}$ & $\begin{array}{c}2.38 \\
(0.42)\end{array}$ & $\begin{array}{c}0.10(10 \mathrm{~mm}) \\
(0.39)\end{array}$ & $\begin{array}{l}1.00 \\
(0.32)\end{array}$ & $\begin{array}{c}1.17 \\
(0.37)\end{array}$ & $\begin{array}{c}-0.18(-18 \\
\mathrm{mm}) \\
(0.22)\end{array}$ \\
\hline $\begin{array}{l}\text { Alveolar click } \\
\text { initial ['!áí] }\end{array}$ & $\begin{array}{c}2.74 \\
(0.39)\end{array}$ & $\begin{array}{c}2.33 \\
(0.24)\end{array}$ & $\begin{array}{c}0.41(41 \mathrm{~mm}) \\
(0.30)\end{array}$ & $\begin{array}{c}0.94 \\
(0.30)\end{array}$ & $\begin{array}{c}0.89 \\
(0.15)\end{array}$ & $\begin{array}{c}0.06(6 \mathrm{~mm}) \\
(0.23)\end{array}$ \\
\hline $\begin{array}{l}\text { Palatal click } \\
\text { initial }\left[\neq \mathbf{f}^{\mathrm{f}} \hat{\mathrm{i}}\right]\end{array}$ & $\begin{array}{c}2.38 \\
(0.76)\end{array}$ & $\begin{array}{c}1.32 \\
(0.32)\end{array}$ & $\begin{array}{c}1.06(106 \mathrm{~mm}) \\
(0.86)\end{array}$ & $\begin{array}{c}0.83 \\
(0.24)\end{array}$ & $\begin{array}{c}0.59 \\
(0.23)\end{array}$ & $\begin{array}{c}0.25(25 \mathrm{~mm}) \\
(0.28)\end{array}$ \\
\hline $\begin{array}{l}\text { Lateral click } \\
\text { initial ["lòi] }\end{array}$ & $\begin{array}{c}2.48 \\
(0.58)\end{array}$ & $\begin{array}{c}2.14 \\
(0.29)\end{array}$ & $\begin{array}{c}0.35(35 \mathrm{~mm}) \\
(0.75)\end{array}$ & $\begin{array}{c}0.87 \\
(0.17)\end{array}$ & $\begin{array}{c}0.84 \\
(0.22)\end{array}$ & $\begin{array}{c}0.04(4 \mathrm{~mm}) \\
(0.21)\end{array}$ \\
\hline $\begin{array}{l}\text { Velar stop } \\
\text { initial[ka] }\end{array}$ & $\begin{array}{c}2.40 \\
(0.28)\end{array}$ & $\begin{array}{c}2.40 \\
(0.23)\end{array}$ & $\begin{array}{c}0.00(0 \mathrm{~mm}) \\
(0.34)\end{array}$ & $\begin{array}{c}0.79 \\
(0.18)\end{array}$ & $\begin{array}{c}0.71 \\
(0.20)\end{array}$ & $\begin{array}{c}0.08(8 \mathrm{~mm}) \\
(0.15)\end{array}$ \\
\hline \multicolumn{7}{|l|}{ Speaker MA } \\
\hline $\begin{array}{l}\text { Dental click } \\
\text { initial ['|íí] }\end{array}$ & $\begin{array}{c}3.41 \\
(0.19)\end{array}$ & $\begin{array}{c}3.08 \\
(0.24)\end{array}$ & $\begin{array}{c}0.33(33 \mathrm{~mm}) \\
(0.15)\end{array}$ & $\begin{array}{c}0.84 \\
(0.13)\end{array}$ & $\begin{array}{c}0.81 \\
(0.15)\end{array}$ & $\begin{array}{c}0.03(3 \mathrm{~mm}) \\
(-0.01)\end{array}$ \\
\hline $\begin{array}{l}\text { Alveolar click } \\
\text { initial ['?!áí] }\end{array}$ & $\begin{array}{c}2.98 \\
(0.21)\end{array}$ & $\begin{array}{l}2.55 \\
(0.27)\end{array}$ & $\begin{array}{c}0.43(43 \mathrm{~mm}) \\
(0.33)\end{array}$ & $\begin{array}{c}0.66 \\
(0.12)\end{array}$ & $\begin{array}{c}0.53 \\
(0.15)\end{array}$ & $\begin{array}{c}0.12(12 \mathrm{~mm}) \\
\quad(0.03)\end{array}$ \\
\hline $\begin{array}{l}\text { Lateral click } \\
\text { initial [\|lə̀ì] }\end{array}$ & $\begin{array}{c}3.11 \\
(0.27)\end{array}$ & $\begin{array}{l}2.99 \\
(0.47)\end{array}$ & $\begin{array}{c}0.11(11 \mathrm{~mm}) \\
\quad(-0.05)\end{array}$ & $\begin{array}{c}0.58 \\
(0.14)\end{array}$ & $\begin{array}{c}0.64 \\
(0.29)\end{array}$ & $\begin{array}{c}-0.05(-5 \mathrm{~mm}) \\
(-0.07)\end{array}$ \\
\hline $\begin{array}{l}\text { Palatal click } \\
\text { initial }\left[\neq \mathbf{f}^{\hat{1}} \hat{\mathbf{i}}\right]\end{array}$ & $\begin{array}{c}2.81 \\
(0.82)\end{array}$ & $\begin{array}{l}1.21 \\
(0.26)\end{array}$ & $\begin{array}{c}1.60(160 \mathrm{~mm}) \\
(0.94)\end{array}$ & $\begin{array}{c}0.64 \\
(0.21)\end{array}$ & $\begin{array}{c}0.46 \\
(0.13)\end{array}$ & $\begin{array}{c}0.19(19 \mathrm{~mm}) \\
(0.05)\end{array}$ \\
\hline Velar stop & 2.83 & 2.81 & $0.02(2 \mathrm{~mm})$ & 0.87 & 0.82 & $0.05(5 \mathrm{~mm})$ \\
\hline Initial [ka] & $(0.23)$ & $(0.24)$ & $(0.20)$ & $(0.26)$ & $(0.32)$ & $(0.13)$ \\
\hline \multicolumn{7}{|l|}{ Speaker TK } \\
\hline $\begin{array}{l}\text { Dental click } \\
\text { initial [ }{ }^{\mathrm{g}} \mid \text { íi] }\end{array}$ & $\begin{array}{c}2.60 \\
(0.27)\end{array}$ & $\begin{array}{c}2.68 \\
(0.25)\end{array}$ & $\begin{array}{c}-0.08(-8 \mathrm{~mm}) \\
(0.19)\end{array}$ & $\begin{array}{c}1.52 \\
(0.34)\end{array}$ & $\begin{array}{c}1.65 \\
(0.38)\end{array}$ & $\begin{array}{c}-0.12(-12 \mathrm{~mm}) \\
(0.21)\end{array}$ \\
\hline $\begin{array}{l}\text { Alveolar click } \\
\text { initial ['9!áí] }\end{array}$ & $\begin{array}{c}2.50 \\
(0.40)\end{array}$ & $\begin{array}{c}2.30 \\
(0.29)\end{array}$ & $\begin{array}{c}0.20(20 \mathrm{~mm}) \\
\quad(0.30)\end{array}$ & $\begin{array}{l}1.39 \\
(0.36)\end{array}$ & $\begin{array}{c}1.24 \\
(0.44)\end{array}$ & $\begin{array}{c}0.15(15 \mathrm{~mm}) \\
\quad(0.31)\end{array}$ \\
\hline $\begin{array}{l}\text { Lateral click } \\
\text { initial [ }{ }^{[\| l \partial ̀ i] ~}\end{array}$ & $\begin{array}{c}2.57 \\
(0.17)\end{array}$ & $\begin{array}{c}2.40 \\
(0.25)\end{array}$ & $\begin{array}{c}0.17(17 \mathrm{~mm}) \\
\quad(0.19)\end{array}$ & $\begin{array}{c}1.52 \\
(0.19)\end{array}$ & $\begin{array}{c}1.44 \\
(0.30)\end{array}$ & $\begin{array}{l}0.08(8 \mathrm{~mm}) \\
(0.29)\end{array}$ \\
\hline $\begin{array}{l}\text { Palatal click } \\
\text { initial }\left[\neq^{6} \mathbf{f}^{\mathrm{f}} \mathbf{i}\right]\end{array}$ & $\begin{array}{c}2.69 \\
(0.24)\end{array}$ & $\begin{array}{c}2.32 \\
(0.17)\end{array}$ & $\begin{array}{c}0.37(37 \mathrm{~mm}) \\
\quad(0.23)\end{array}$ & $\begin{array}{c}1.81 \\
(0.18)\end{array}$ & $\begin{array}{c}1.37 \\
(0.15)\end{array}$ & $\begin{array}{c}0.43(43 \mathrm{~mm}) \\
\quad(0.23)\end{array}$ \\
\hline $\begin{array}{l}\text { Velar stop } \\
\text { initial [ka] }\end{array}$ & $\begin{array}{c}3.68 \\
(0.48)\end{array}$ & $\begin{array}{c}3.70 \\
(0.33)\end{array}$ & $\begin{array}{c}-0.02(-2 \mathrm{~mm}) \\
(0.38)\end{array}$ & $\begin{array}{c}2.58 \\
(0.27)\end{array}$ & $\begin{array}{c}2.62 \\
(0.15)\end{array}$ & $\begin{array}{c}-0.05(-5 \mathrm{~mm}) \\
(0.16)\end{array}$ \\
\hline
\end{tabular}


Table B. Tongue Dorsum Constriction Location at T2 against syllable type, comparing the palatal click type with the other three pre-palatal click types

\begin{tabular}{|c|c|c|c|c|c|}
\hline Speaker & Comparison & Estimate & Std. Error & $\mathrm{T}$ value & $\operatorname{Pr}(>/ t /)$ \\
\hline \multirow[t]{3}{*}{$\mathrm{JF}$} & [キihi] vs. [glíi] & 1.07 & 0.14 & 7.4 & * \\
\hline & [‡ini] vs. [g!éí] & 1.02 & 0.15 & 6.6 & * \\
\hline & [‡i^ì] vs. [gllə̀ì] & 0.82 & 0.14 & 5.9 & * \\
\hline \multirow[t]{3}{*}{$\mathrm{MA}$} & [†ihij] vs. [glíí] & 1.86 & 0.13 & 14.73 & * \\
\hline & [‡ihi] vs. [g!éí] & 1.33 & 0.14 & 9.31 & * \\
\hline & [†ini] vs. [g\|l̀̀i] & 1.78 & 0.13 & 14.04 & * \\
\hline \multirow[t]{3}{*}{ TK } & [キihi] vs. [glíi] & 0.67 & .12 & 5.41 & $*$ \\
\hline & [‡ini] vs. [g!éí] & 0.17 & .12 & 1.39 & NS \\
\hline & [‡ini] vs. [gllèì] & -0.20 & .12 & -1.65 & NS \\
\hline
\end{tabular}

Table C. Differences between the Tongue Dorsum Constriction Location at T2 in ' $k$ ' in ka and the four click-initial syllable types (numbers are in $\mathrm{cm}$ )

\begin{tabular}{|c|c|c|c|c|c|}
\hline $\begin{array}{l}\text { Speake } \\
r\end{array}$ & Comparison & Estimate & Std. Error & T value & $\operatorname{Pr}(>/ t /)$ \\
\hline JF & 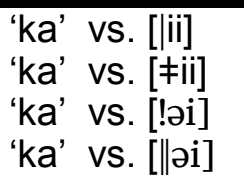 & $\begin{array}{l}-0.02 \\
-1.09 \\
-0.07 \\
-0.27\end{array}$ & $\begin{array}{l}0.13 \\
0.14 \\
0.14 \\
0.12\end{array}$ & $\begin{array}{l}-0.15 \\
-7.99 \\
-0.51 \\
-2.24\end{array}$ & $\begin{array}{c}\text { NS } \\
* \\
\text { NS } \\
*\end{array}$ \\
\hline $\mathrm{MA}$ & 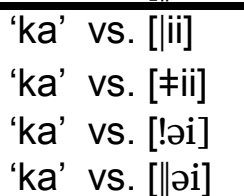 & $\begin{array}{c}0.27 \\
-1.60 \\
-0.27 \\
0.18\end{array}$ & $\begin{array}{l}0.94 \\
0.13 \\
0.15 \\
0.14\end{array}$ & $\begin{array}{c}1.92 \\
-12.05 \\
-1.75 \\
1.29\end{array}$ & $\begin{array}{c}\text { NS } \\
* \\
\text { NS } \\
\text { NS }\end{array}$ \\
\hline$\overline{\mathrm{TK}}$ & 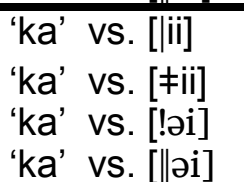 & $\begin{array}{l}-0.59 \\
-1.27 \\
-1.09 \\
-1.47\end{array}$ & $\begin{array}{l}0.14 \\
0.14 \\
0.14 \\
0.14\end{array}$ & $\begin{array}{c}-4.26 \\
-9.08 \\
-7.84 \\
-10.55\end{array}$ & $\begin{array}{l}\text { * } \\
\text { * } \\
\text { * } \\
\text { * }\end{array}$ \\
\hline
\end{tabular}

Table D. Tongue Dorsum Height at T2 regressed against syllable type (palatal click type compared with the three pre-palatal click types)

\begin{tabular}{|c|c|c|c|c|c|}
\hline Speaker & Comparison & Estimate & Std. Error & T value & $\operatorname{Pr}(>/ t /)$ \\
\hline \multirow[t]{3}{*}{$\mathrm{JF}$} & [キihi] vs. [glíi] & 0.37 & 0.08 & 4.50 & $*$ \\
\hline & [キihi] vs. [g!éí] & 0.18 & 0.09 & 2.10 & $*$ \\
\hline & [†ihi] vs. [gllèi] & 0.24 & 0.08 & 3.15 & $*$ \\
\hline \multirow[t]{3}{*}{ MA } & [‡ihi] vs. [glíí] & 0.83 & 0.10 & 8.59 & $*$ \\
\hline & [キihi] vs. [g!óí] & 0.43 & 0.11 & 3.99 & $*$ \\
\hline & [キihi] vs. [gllèì] & 0.63 & 0.10 & 6.52 & $*$ \\
\hline \multirow[t]{3}{*}{ TK } & [‡ihi] vs. [glíí] & 0.02 & 0.09 & 0.80 & NS \\
\hline & [‡ihi] vs. [g!éí] & -0.27 & 0.09 & -3.11 & $*$ \\
\hline & [キihi] vs. [gllèi] & -0.05 & 0.09 & -0.53 & NS \\
\hline
\end{tabular}


Table E. Position of farthest back position of the Tongue Root at $T 2$ regressed against syllable type, comparing the palatal click initial syllable type to the other three pre-palatal click initial syllable types

\begin{tabular}{|c|c|c|c|c|c|}
\hline Speaker & Comparison & Estimate & Std. Error & $\mathrm{T}$ value & $\operatorname{Pr}(>/ t /)$ \\
\hline JF & 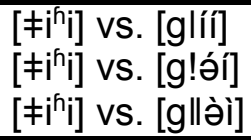 & $\begin{array}{l}0.59 \\
0.30 \\
0.25\end{array}$ & $\begin{array}{l}0.11 \\
0.12 \\
0.11\end{array}$ & $\begin{array}{l}5.11 \\
2.46 \\
2.27\end{array}$ & $\begin{array}{l}* \\
* \\
*\end{array}$ \\
\hline MA & 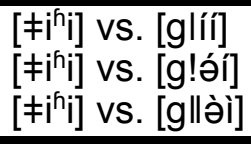 & $\begin{array}{l}0.35 \\
0.07 \\
0.18 \\
\end{array}$ & $\begin{array}{l}0.07 \\
0.08 \\
0.07 \\
\end{array}$ & $\begin{array}{l}4.68 \\
0.88 \\
2.36 \\
\end{array}$ & $\begin{array}{l}* \\
\text { NS } \\
*\end{array}$ \\
\hline TK & 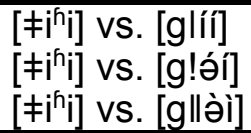 & $\begin{array}{r}0.60 \\
0.23 \\
-0.03\end{array}$ & $\begin{array}{l}0.15 \\
0.15 \\
0.15\end{array}$ & $\begin{array}{l}3.95 \\
1.52 \\
-0.20\end{array}$ & NS \\
\hline
\end{tabular}

Table F. Differences between the Tongue Root Constriction Location at T2 in ' $k$ ' in ka and the four click-initial syllable types (numbers are in $\mathrm{cm}$ )

\begin{tabular}{|c|c|c|c|c|c|}
\hline $\begin{array}{l}\text { Speake } \\
r\end{array}$ & Comparison & Estimate & Std. Error & T value & $\operatorname{Pr}(>/ t /)$ \\
\hline JF & $\begin{array}{ll}\text { 'ka' } & \text { vs. [lii] } \\
\text { 'ka' vs. [キii] } \\
\text { 'ka' vs. [!əi] } \\
\text { 'ka' vs. [\|əi] }\end{array}$ & $\begin{array}{c}0.46 \\
-0.12 \\
0.18 \\
0.13\end{array}$ & $\begin{array}{l}0.10 \\
0.11 \\
0.11 \\
0.10\end{array}$ & $\begin{array}{c}4.59 \\
-1.12 \\
1.64 \\
1.32\end{array}$ & $\begin{array}{l}{ }^{*} \\
\text { NS } \\
\text { NS } \\
\text { NS }\end{array}$ \\
\hline $\mathrm{MA}$ & $\begin{array}{l}\text { 'ka' vs. [lii] } \\
\text { 'ka' vs. [キii] } \\
\text { 'ka' vs. [!əi] } \\
\text { 'ka' vs. [\|əi] }\end{array}$ & $\begin{array}{l}-0.01 \\
-0.36 \\
-0.28 \\
-0.18\end{array}$ & $\begin{array}{l}0.10 \\
0.09 \\
0.11 \\
0.10\end{array}$ & $\begin{array}{l}-0.07 \\
-3.90 \\
-2.68 \\
-1.89\end{array}$ & $\begin{array}{c}\text { NS } \\
* \\
* \\
\text { NS }\end{array}$ \\
\hline TK & $\begin{array}{ll}\text { 'ka' } & \text { vs. [lii] } \\
\text { 'ka' vs. [キii] } \\
\text { 'ka' vs. [!əi] } \\
\text { ‘ka' vs. [\|əi] }\end{array}$ & $\begin{array}{l}-0.6 \\
-1.20 \\
-0.97 \\
-1.23\end{array}$ & $\begin{array}{l}0.14 \\
0.14 \\
0.14 \\
0.14\end{array}$ & $\begin{array}{l}-4.27 \\
-8.51 \\
-6.88 \\
-8.73\end{array}$ & $\begin{array}{l}* \\
* \\
* \\
*\end{array}$ \\
\hline
\end{tabular}

Table G. Tongue Root Height at T2 regressed against syllable type, comparing the palatal click initial syllable type to the pre-palatal click initial syllable types

\begin{tabular}{|c|c|c|c|c|c|}
\hline Speaker & Comparison & Estimate & Std. Error & T value & $\operatorname{Pr}(>/ t /)$ \\
\hline \multirow[t]{3}{*}{$\mathrm{JF}$} & [キifi] vs. [glíí] & -0.05 & 0.16 & -0.33 & NS \\
\hline & [キihi] vs. [g!éí] & -0.42 & 0.17 & -2.52 & * \\
\hline & {$\left[\neq i i_{i}\right]$ vs. [gllèì] } & -0.26 & 0.15 & -1.72 & NS \\
\hline \multirow[t]{3}{*}{ MA } & [‡ifi] vs. [glíí] & .63 & .20 & 3.12 & * \\
\hline & [†ini] vs. [g!áí] & .11 & .23 & .47 & NS \\
\hline & [‡ihi] vs. [gllò̀] & .36 & .20 & 1.81 & NS \\
\hline \multirow[t]{3}{*}{ TK } & [‡ifi] vs. [glíí] & .06 & .27 & 0.24 & NS \\
\hline & [‡ini ] vs. [g!éí] & -.70 & .27 & -2.53 & * \\
\hline & [‡ihi] vs. [gllèì] & -.13 & .27 & -0.19 & NS \\
\hline
\end{tabular}


Table H. Differences between the Tongue Dorsum Constriction Locations at T1-T2 regressed against anterior constriction location, comparing palatal vs. pre-palatal click types

\begin{tabular}{|c|c|c|c|c|c|}
\hline Speaker & Comparison & Estimate & Std. Error & $\mathrm{T}$ value & $\operatorname{Pr}(>/ t /)$ \\
\hline JF & $\{[\neq]\}$ vs. $\{[\mid],[!],[\|]\}$ & -7.8 & 2.3 & -3.4 & * \\
\hline MA & $\{[\neq]\}$ vs. $\{[\mid],[!],[\|]\}$ & -13.2 & 1.9 & -6.8 & * \\
\hline TK & $\{[\neq]\}$ vs. $\{[\mid],[!],[\|]\}$ & -3.3 & 1.3 & -2.5 & * \\
\hline
\end{tabular}

Table I. Differences between the Tongue Dorsum Constriction Locations at T1-T2 regressed against syllable type, comparing [ka] to the four click-initial syllable types (numbers are in $\mathrm{mm}$ )

\begin{tabular}{|c|c|c|c|c|c|}
\hline Speaker & Comparison & Estimate & Std. Error & T value & $\operatorname{Pr}(>/ t /)$ \\
\hline \multirow[t]{4}{*}{$\mathrm{JF}$} & 'ka' vs. [lii] & 25.0 & 2.3 & 10.8 & * \\
\hline & 'ka' vs. [キii] & 34.7 & 2.5 & 13.8 & * \\
\hline & 'ka' vs. [!əi] & 28.1 & 2.5 & 11.2 & * \\
\hline & ‘ka' vs. [\|əi] & 27.5 & 2.2 & 12.5 & * \\
\hline \multirow[t]{4}{*}{ MA } & 'ka' vs. [lii] & 3.1 & 2.5 & 1.2 & NS \\
\hline & 'ka' vs. [‡ii] & 15.8 & 2.4 & 6.5 & * \\
\hline & ‘ka' vs. [!əi] & 4.1 & 2.8 & 1.5 & NS \\
\hline & ‘ka' vs. [\|əəi] & 0.9 & 2.6 & 0.4 & NS \\
\hline \multirow[t]{4}{*}{ TK } & 'ka' vs. [lii] & 0 & 0.2 & -0.2 & NS \\
\hline & 'ka' vs. [‡ii] & 0.5 & 0.2 & 3.2 & * \\
\hline & 'ka' vs. [!əoi] & 0.2 & 0.2 & 1.5 & NS \\
\hline & 'ka' vs. [\|əoi] & 0.3 & 0.2 & 2.0 & NS \\
\hline
\end{tabular}

Table J. Difference between horizontal Tongue Root positions at T1-T2 regressed against anterior constriction location, comparing syllables containing palatal vs. pre-palatal click types

\begin{tabular}{|c|c|c|c|c|c|}
\hline Speaker & Comparison & Estimate & Std. Error & T value & $\operatorname{Pr}(>/ t /)$ \\
\hline $\begin{array}{l}\text { JF } \\
\text { MA }\end{array}$ & $\begin{array}{l}\{[\neq]\} \text { vs. }\{[\mid],[!],[\|]\} \\
\{[\neq]\} \text { vs. }\{[\mid],[!],[\|]\}\end{array}$ & $\begin{array}{l}-2.7 \\
-1.6\end{array}$ & $\begin{array}{l}0.9 \\
0.8\end{array}$ & $\begin{array}{l}-2.98 \\
-2.16\end{array}$ & * \\
\hline TK & $\{[\neq]\}$ vs. $\{[\mid],[!],[\|]\}$ & -4.8 & 1.3 & -3.82 & * \\
\hline
\end{tabular}

Table K. Differences between the Tongue Root Constriction Location at T2 against syllable type, comparing ka with the four click initial syllable types (numbers are in $\mathrm{mm}$ )

\begin{tabular}{|c|c|c|c|c|c|}
\hline Speaker & Comparison & Estimate & Std. Error & $\mathrm{T}$ value & $\operatorname{Pr}(>/ t /)$ \\
\hline JF & $\begin{array}{l}\text { [ka] vs. [glíí] } \\
\text { [ka] vs. [キihi] } \\
\text { [ka] vs. [g!éí] } \\
\text { [ka] vs. [gllèi] }\end{array}$ & $\begin{array}{l}5.3 \\
9.5 \\
7.6 \\
7.4\end{array}$ & $\begin{array}{c}0.9 \\
1 \\
1 \\
0.9\end{array}$ & $\begin{array}{l}5.8 \\
9.6 \\
7.7 \\
7.5\end{array}$ & $\begin{array}{l}* \\
* \\
* \\
*\end{array}$ \\
\hline MA & $\begin{array}{l}\text { [ka] vs. [glíí] } \\
\text { [ka] vs. [キini] } \\
\text { [ka] vs. [g!éí] } \\
\text { [ka] vs. [gllèi] }\end{array}$ & $\begin{array}{r}-0.2 \\
1.3 \\
0.7 \\
-1.1 \\
\end{array}$ & $\begin{array}{c}1 \\
1 \\
1.1 \\
1 \\
\end{array}$ & $\begin{array}{l}-0.2 \\
1.4 \\
0.7 \\
-1.0\end{array}$ & $\begin{array}{l}\text { NS } \\
\text { NS } \\
\text { NS } \\
\text { NS }\end{array}$ \\
\hline TK & $\begin{array}{l}\text { [ka] vs. [glíí] } \\
\text { [ka] vs. [キini] } \\
\text { [ka] vs. [g!éí] } \\
\text { [ka] vs. [gllèi] }\end{array}$ & $\begin{array}{l}-0.3 \\
5.8 \\
1.2 \\
2.2\end{array}$ & $\begin{array}{l}1.4 \\
1.4 \\
1.4 \\
1.4\end{array}$ & $\begin{array}{l}-0.2 \\
4.1 \\
0.8 \\
1.6\end{array}$ & $\begin{array}{c}\text { NS } \\
* \\
N S \\
N S\end{array}$ \\
\hline
\end{tabular}

